DNA Library of Life, research article

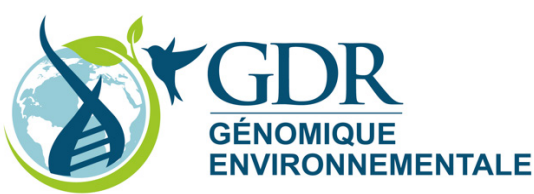

urn:1sid:zoobank.org:pub:DEFAD552-9C2E-497B-83CA-1E04E3353EA4

\title{
Comparative phylogeography of bamboo bats of the genus Tylonycteris (Chiroptera, Vespertilionidae) in Southeast Asia
}

\author{
Vuong Tan TU ${ }^{1}$, Gábor CSORBA ${ }^{2}$, Manuel RUEDI ${ }^{3}$, Neil M. FUREY ${ }^{4}$, \\ Nguyen Truong SON ${ }^{5}$, Vu Dinh THONG $^{6}$, Céline BONILLO ${ }^{7} \&$ Alexandre HASSANIN ${ }^{8, *}$ \\ ${ }^{1,5,6}$ Institute of Ecology and Biological Resources, Vietnam Academy of Science and Technology, \\ 18 Hoang Quoc Viet Road, Cau Giay District, Hanoi, Vietnam. \\ 1,7,8 Muséum national d'Histoire naturelle, Service de Systématique Moléculaire, \\ UMS 2700, CP 26, 43, Rue Cuvier, 75005 Paris, France. \\ ${ }_{1,8}^{1}$ Institut de Systématique, Evolution, Biodiversité (ISYEB), Sorbonne Universités, \\ UMR 7205 MNHN CNRS UPMC, Muséum national d'Histoire naturelle, \\ CP 51, 55, Rue Buffon, 75005 Paris, France. \\ ${ }^{2}$ Department of Zoology, Hungarian Natural History Museum, Baross u. 13, 1088 Budapest, Hungary. \\ ${ }^{3}$ Department of Mammalogy and Ornithology, Natural History Museum of Geneva, \\ Route de Malagnou 1, BP 6434, 1211 Geneva 6, Switzerland. \\ ${ }^{4}$ Fauna \& Flora International, Cambodia Programme, 19 Street 360, BKK 1, \\ Chamkarmorn, Phnom Penh, Cambodia. \\ *Corresponding author: alexandre.hassanin@mnhn.fr \\ ${ }^{1}$ Email: tuvuongtan@gmail.com \\ ${ }^{2}$ Email: csorba.gabor@nhmus.hu \\ ${ }^{3}$ Email: Manuel.Ruedi@,ville-ge.ch \\ ${ }^{4}$ Email: n.furey.ffi@gmail.com \\ ${ }^{5}$ Email: truongsoniebr@gmail.com \\ ${ }^{6}$ Email: thong@iebr.ac.vn \\ ${ }^{7}$ Email: bonillo@mnhn.fr

\footnotetext{
${ }^{1}$ urn:Isid:zoobank.org:author:3C6F72F2-CA28-4468-8A03-BB0214CBFB13

${ }^{2}$ urn:Isid:zoobank.org:author:4B97570F-5A7D-447A-8810-B67C5E6F7CC0

${ }^{3}$ urn:Isid:zoobank.org:author:A87D0170-5333-4A1A-B9A8-42AADB4EFDCA

${ }^{4}$ urn:lsid:zoobank.org:author:67F4248B-AEE9-41DC-AE4F-EE81C4561956

${ }^{5}$ urn:1sid:zoobank.org:author:A52E73CA-D94C-4742-B691-692E0B828B53

${ }^{6}$ urn:1sid:zoobank.org:author:0BAFD329-DA4E-4FCA-925F-336E7F7CCB83

7 urn:lsid:zoobank.org:author:7333D242-0714-41D7-B2DB-6804F8064B13
} \\ ${ }^{8}$ urn:lsid:zoobank.org:author:0DCC3E08-B2BA-4A2C-ADA5-1A256F24DAA1
}

\begin{abstract}
In Southeast Asia, bats of the genus Tylonycteris Peters, 1872 have traditionally been classified into two wide-ranging species, T. pachypus (Temminck, 1840) and T. robustula Thomas, 1915. Our comparative phylogeographic analyses based on two mitochondrial and seven nuclear genes, combined with our multivariate morphological analyses, show that these species actually represent cryptic species complexes that share a similar biogeographic history in three major regions, i.e., Sundaland, southern
\end{abstract}


Indochina, and northern Indochina. Our molecular dating estimates suggest that Pleistocene climatic oscillations and sea level changes have repeatedly isolated ancestral populations of Tylonycteris spp. in distant bamboo forest refugia. The analyses indicate, however, that populations of the T. pachypus complex were less affected by forest fragmentation in mainland Southeast Asia than those of the T. robustula complex. Accordingly, we propose several taxonomic changes within the genus Tylonycteris: the species T. fulvida and T. malayana are revalidated, and a new species, T. tonkinensis Tu, Csorba, Ruedi \& Hassanin sp. nov., endemic to northern Indochina, is described.

Keywords. Vespertilioninae, Tylonycteris, DNA phylogeny, taxonomy, biogeography.

Tu V.T., Csorba G., Ruedi M., Furey N.M., Son N.T., Thong V.D., Bonillo C. \& Hassanin A. 2017. Comparative phylogeography of bamboo bats of the genus Tylonycteris (Chiroptera, Vespertilionidae) in Southeast Asia. European Journal of Taxonomy 274: 1-38. http://dx.doi.org/10.5852/ejt.2017.274

\section{Introduction}

Bamboo bats of the genus Tylonycteris Peters, 1872 (Chiroptera, Vespertilionidae) are small-sized bats (weight: 3-10 g; forearm length: $22-32 \mathrm{~mm}$ ) characterized by a dorsoventrally flattened skull and well-developed, fleshy pads at the base of the thumb and on the sole of the foot (Tate 1942). These morphological features are thought to be adaptations for roosting in small cavities with smooth surfaces such as the internodes of bamboo stalks or narrow crevices in trees and rocks (Feng et al. 2008; Medway \& Marshall 1970; Thewissen \& Etnier 1995). Classically, the genus was regarded as containing only two species, T. pachypus (Temminck, 1840) and T. robustula Thomas, 1915, with several further taxa included as subspecies (Fig. 1) (Tate 1942; Simmon 2005). More recently, Feng et al. (2008) described a third species, T. pygmaea Feng, Li \& Wang, 2008, which is smaller than its congeners. Whereas T. pygmaea is considered to be endemic to Yunnan Province in southern China, the two other species have much more extensive geographic ranges that greatly overlap in Southeast Asia (Fig. 1). The range of T. pachypus is even more extended in the north and west, with apparently two isolated populations recorded in the Chinese provinces of Sichuan and Chongqing, and in southern India around the Western Ghats (Fig. 1) (Bates et al. 2008a, 2008b).

Bats of the genus Tylonycteris are usually associated with bamboo groves in both intact and disturbed habitats at elevations ranging from lowland up to $1500 \mathrm{~m}$ (Bates et al. 2008a, 2008b; Medway \& Marshall 1970). All species can often be found roosting within bamboo internodes in colonies of up to 40 individuals, entering through narrow vertical slits created by long-horned beetles (Medway \& Marshall 1970; Zhang et al. 2007). Females are gregarious, whereas males tend to be more solitary (Medway \& Marshall 1972). At least occasionally, different species of Tylonycteris can occupy the same bamboo chamber (Feng et al. 2008; Medway \& Marshall 1970). Zhang et al. (2005) determined that the diet of Tylonycteris bats is mainly composed of insects of the order Hymenoptera, which were regarded as significant pests of bamboo. Interestingly, the highest richness in bamboo species in the Asia-Pacific Region has been recorded in southern China (Bystriakova et al. 2003a; Yuming et al. 2004), the only region where the three species of Tylonycteris occur in sympatry. Taken together, these aspects indicate that Tylonycteris species are strongly dependent on bamboo vegetation.

DNA barcodes corresponding to the 5' fragment of the mitochondrial DNA (mtDNA) gene of cytochrome c oxidase subunit I (COI) have been shown to be useful in species identification. Those published by Francis et al. (2010) for 9 and 15 samples of T. pachypus and T. robustula, respectively, have revealed high levels of intraspecific genetic variation in both taxa, suggesting the possible existence of cryptic species. More recently, Huang et al. (2014) showed that bats assigned to T. pachypus fulvida (Blyth, 1859) collected from South China and nearby regions differed karyotypically and morphologically from 

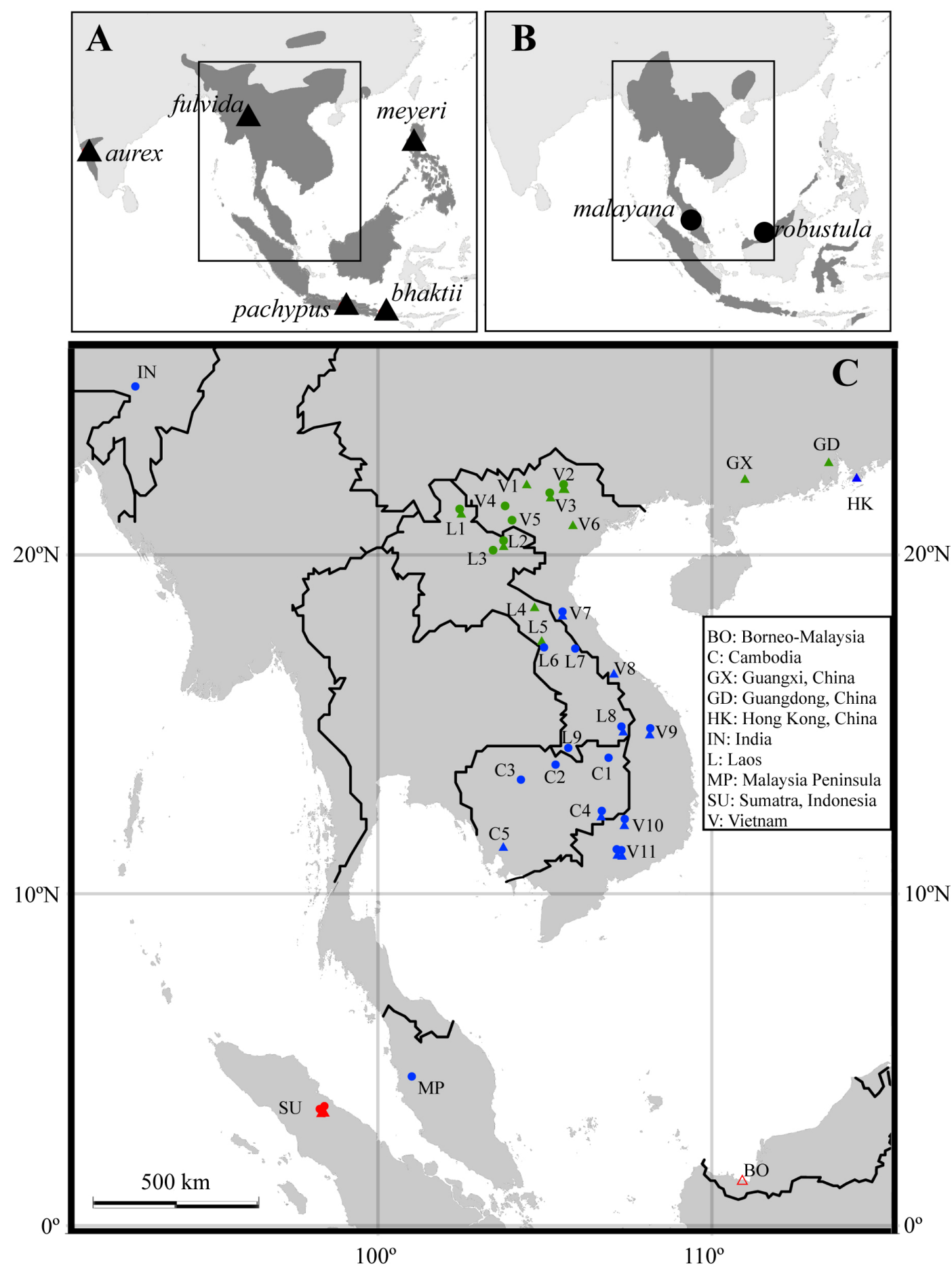

\section{mtDNA haplogroups}

- T. pachypus: $\Delta$ - Sumatra (Tp1), $\Delta$ - Borneo, $\Delta$ - South Indo-Burma (Tp2), $\Delta$ - North Indo-Burma (Tp3)

- T. robustula: - Sumatra ( $\operatorname{Tr} 1), \bullet-$ South + West Indo-Burma (Tr2), ๑ - North Indo-Burma ( $\operatorname{Tr} 3)$

Fig. 1. A-B. Maps of Asia showing the distribution range (shaded) and type localities of described subspecies of T. pachypus (Temminck, 1840) and T. robustula Thomas, 1915 (Bates et al. 2008a, 2008b). C. Localities of Tylonycteris specimens included in this study. Triangles and circles refer to T. pachypus and T. robustula, respectively; the colours indicate the mtDNA haplogroups found in the Bayesian analyses of $C O I$ and $C y t b$ sequences (see Fig. 2 for details). 
T. p. pachypus found in Peninsular Malaysia and Indonesia, suggesting that T. pachypus might be a species complex.

We present here a comprehensive comparative phylogeographic investigation of Tylonycteris spp. based on molecular and morphological data. Two mitochondrial markers and seven nuclear markers were sequenced to address the following questions: (1) how many mtDNA haplogroups exist in mainland Southeast Asia; (2) are these haplogroups corroborated by nuclear DNA markers; and (3) do these genetically defined groups correspond to distinct morphotypes? The ultimate goal of this study was to improve our understanding of the biogeography and taxonomy of the genus Tylonycteris.

\section{Material and methods}

\section{Data sampling for genetic analyses}

For this study, 63 tissue samples were collected during field expeditions within Indochina and from historical specimens housed in museum collections. Vouchers were deposited in the following institutions: the Institute of Ecology and Biological Resources (IEBR, Hanoi, Vietnam), the Muséum national d'Histoire naturelle (MNHN, Paris, France), the Muséum d'histoire naturelle de Genève (MHNG, Geneva, Switzerland), the Hungarian Natural History Museum (HNHM, Budapest, Hungary), the Centre for Biodiversity Conservation (CBC, Royal University of Phnom Penh, Cambodia), Rijksmuseum van Natuurlijke Histoire (RMNH, Leiden, Netherlands; now Naturalis Biodiversity Center) and the Zoological Museum Amsterdam (ZMA, Amsterdam, Netherlands). In addition, we included DNA sequences of Tylonycteris available in the GenBank nucleotide database. The origins of all samples are represented in Fig. 1 and detailed in Appendices 1 and 2.

Bats were captured using mist nets (Ecotone, Poland) and four-bank harp traps. They were measured, photographed and initially identified following morphological criteria provided by Bates \& Harrison (1997), Borisenko \& Kruskop (2003) and Francis (2008). Tissue samples for genetic study were collected from chest muscles of voucher specimens or from the patagium (biopsy punches; $3 \mathrm{~mm}$ diameter) of released bats. Tissue samples were preserved in $95 \%$ ethanol and stored at $-20^{\circ} \mathrm{C}$.

\section{DNA extraction, amplification, sequencing}

Total DNA was extracted from muscle or patagium samples using the QIAGEN DNAeasy Tissue Kit (Qiagen, Hilden, Germany) according to the manufacturer's protocol. Two mitochondrial genes were sequenced for this study: the 5' fragment of the COI gene and the complete cytochrome b $(C y t b)$ gene. The primers used for PCR amplification of mitochondrial genes were UTyrLA and C1L705 for COI (Hassanin et al. 2012), and Thr-CH (Hassanin et al. 2014) and the newly designed Glu-CH (5'-AAY CAC CGT TGT AYT TCA ACT A-3') for Cytb. From DNA extracted from five old museum vouchers, it was not possible to amplify long PCR fragments (>300 nt). Therefore, two further primer sets were used to amplify and sequence two overlapping fragments of COI: UTyrLA and Tyl-L122 (5'-AGY ART GCT CCT GGY TGA CC-3'), and Tyl-U86 (5'-GGT GCC TGA GCT GGC ATA GT-3') and Tyl-L266 (5'-TCG GGG RAA TGC TAT ATC AG-3').

The following seven nuclear markers were also sequenced for three outgroup species and 14 samples of Tylonycteris representing the divergent mtDNA haplotypes of Indochina: intron 2 of CHPF2 (chondroitin polymerizing factor 2), intron 6 of HDAC1 (histone deacetylase 1), intron 10 of HDAC2 (histone deacetylase 2), intron 2 of PABPN1 (poly(A) binding protein, nuclear 1), intron 6 of RIOK3 (RIO kinase 3), intron 9 of TUFM (elongation factor Tu, mitochondrial precursor), and intron 6 of ZFYVE27 (zinc finger, FYVE domain containing 27). The primers used for PCR amplifications of nuclear introns are detailed in Hassanin et al. (2013). For Sumatran specimens, which were collected more than one hundred years ago, it was not possible to obtain successful PCR amplification of nuclear markers. 
TU V.T. et al., Phylogeography of Tylonycteris in Southeast Asia

Amplifications were done in $20 \mu \mathrm{l}$ using $3 \mu \mathrm{l}$ of Buffer $10 \mathrm{X}$ with $\mathrm{MgCl}_{2}, 2 \mu \mathrm{l}$ of dNTP $(6.6 \mathrm{mM})$, $0.12 \mu \mathrm{l}$ of Taq DNA polymerase (2.5 U, Qiagen, Hilden, Germany) and $0.5-1.0 \mu 1$ of the two primers at $10 \mu \mathrm{M}$. The standard PCR conditions were as follows: $4 \mathrm{~min}$ at $95^{\circ} \mathrm{C} ; 5$ cycles of denaturation/ annealing/extension for $45 \mathrm{~s}$ at $95^{\circ} \mathrm{C}, 1 \mathrm{~min}$ at $60^{\circ} \mathrm{C}$ and $1 \mathrm{~min}$ at $72^{\circ} \mathrm{C}$, followed by 30 cycles of $30 \mathrm{~s}$ at $95^{\circ} \mathrm{C}, 45 \mathrm{~s}$ at $55^{\circ} \mathrm{C}$, and $1 \mathrm{~min}$ at $72^{\circ} \mathrm{C}$, followed by $10 \mathrm{~min}$ at $72^{\circ} \mathrm{C}$. PCR products were resolved by electrophoresis on a $1.5 \%$ agarose gel stained with ethidium bromide and visualized under UV light. Both strands of PCR products were sequenced using Sanger sequencing on an ABI 3730 automatic sequencer at the Centre National de Séquençage (Genoscope) in Evry (France). The sequences were edited and assembled using Codoncode Alignment v. 3.7.1 (CodonCode Corporation) and Sequencher v. 5.0 (Gene Codes Corporation). Heterozygous positions (double peaks) were scored using the IUPAC ambiguity codes. Sequences generated for this study were deposited in the GenBank database (accession numbers KX496340-KX496537; Appendix 1).

\section{Phylogeographic analyses based on mitochondrial sequences}

The 63 COI and 19 Cytb sequences newly generated in this study were compared to the 38 COI and four $C y t b$ sequences available for Tylonycteris in GenBank. DNA sequences were aligned with Se-Al v. 2.0a11 (Rambaut 2002). Phylogenetic analyses of bats of the genus Tylonycteris were initially performed using two separate datasets: (1) COI (101 taxa and $728 \mathrm{nt}$ ), and (2) Cytb (23 taxa and $1140 \mathrm{nt}$ ). Three newly sequenced species, representing three different genera of the subfamily Vespertilioninae (Pipistrellus $\mathrm{cf}$. javanicus Gray, 1838, Eptesicus sp. and Hypsugo pulveratus (Peters, 1870)), were chosen as outgroups on the basis of previous studies (Jones et al. 2002; Roehrs et al. 2010).

The Bayesian approach was used to reconstruct phylogenetic relationships. The best-fitting model of sequence evolution was selected under jModelTest (Posada 2008) using the Akaike Information Criterion (AIC). Bayesian analyses were then conducted with MrBayes v. 3.2.1 (Ronquist et al. 2012) using the selected HKY $+\mathrm{G}$ and GTR $+\mathrm{I}+\mathrm{G}$ models, respectively for $\mathrm{COI}$ and $C y t b$ datasets. The posterior probabilities (PP) were calculated using four independent Markov chains run for 10000000 Metropolis-coupled MCMC generations, with trees sampled every 1000 generations and a burn-in of $25 \%$. Pairwise genetic distances between groups were calculated with PAUP* v. 4 b10 (Swofford 2003) using the Kimura 2-parameter (K2P) correction.

\section{Phylogenetic analyses based on eight independent markers}

The phylogeny of Tylonycteris was further investigated using a reduced sample of 14 specimens (plus three outgroups) sequenced for multiple loci, including seven nuclear introns and a combination of two mtDNA markers (Appendix 1). These analyses were performed to test possible discordance between the phylogenetic signals extracted from independent markers. We did not obtain high quality sequences for three PCR products: CHPF2 for two specimens of T. pachypus (T5009 and VN11-1138) and PABPNI for Eptesicus sp. (VN11-0076) (Appendix 1). These poor-quality sequences were not included in the alignments and coded as missing data (Ns) in the multilocus analyses. Accordingly, 10 datasets were analyzed: supermatrix (combining all the nine genes; $7572 \mathrm{nt}$ ), nuDNA (combining all the seven nuclear introns; $5604 \mathrm{nt})$, mtDNA (COI + Cytb; $1868 \mathrm{nt})$, CHPF2 (858 nt), HDACl (1128 nt), HDAC2 (639 nt), PABPNI (677 nt), RIOK3 (915 nt), TUFM (655 nt) and ZFYVE27 (732 nt). DNA alignments were done with Se-Al v. 2.0a11 (Rambaut 2002). A few gaps were included in the alignments of the nuclear introns, but their positions were not found to be ambiguous. The models of nucleotide evolution were selected under jModeltest (Posada 2008): the GTR $+\mathrm{I}+\mathrm{G}$ model for $m t D N A$ markers, the HYK $+\mathrm{G}$ model for CHPF2, PABPNI and ZFYVE27, and the HKY model for HDAC1, HDAC2, RIOK3 and TUFM.

A partitioned Bayesian approach was used to account for the combination of markers with contrasted molecular properties. The mtDNA dataset was run using a GTR $+\mathrm{I}+\mathrm{G}$ model for each of the three codon 
positions of the two mitochondrial genes; the concatenation of seven nuclear introns and the supermatrix were run using the selected model for each gene partition. The indels shared by at least two taxa and without ambiguity in the position of the gaps were coded as additional characters ("1": insertion; " 0 ": deletion) and analyzed as a separate partition in the Bayesian analyses. The posterior probabilities (PP) were calculated using four independent Markov chains run for 10000000 Metropolis-coupled MCMC generations, with tree sampling every 1000 generations, and a burn-in of $25 \%$.

Bootstrap percentages (BP) were computed by PAUP* v. 4 b10 (Swofford 2003) after 1000 replicates, using the GTR $+\mathrm{I}+\mathrm{G}$ model selected by jModelTest for the supermatrix dataset. The results obtained from the separate Bayesian analyses of the eight independent molecular markers (mtDNA and the seven nuclear introns) were also analyzed for congruence using the SuperTRI method (Ropiquet et al. 2009). The lists of bipartitions obtained from the eight Bayesian analyses were transformed into a weighted binary matrix for supertree construction using SuperTRI v. 57 (available from http://www.normalesup. org/ bli/Programs/programs.html). Each binary character corresponds to a node, which was weighted according to its frequency of occurrence in one of the eight lists of bipartitions. In that way, the SuperTRI method takes into account both principal and secondary signals, because all phylogenetic hypotheses found during the eight separate analyses are represented in the weighted binary matrix used for supertree construction. The reliability of the nodes was assessed using three different measures. The first value is the Supertree Bootstrap Percentage (SBP), which was calculated under PAUP* v. 4b10 after 1000 BP replicates of the weighted binary matrix reconstructed with SuperTRI (941 characters; heuristic search). The second value is the "Mean Posterior Probability" (MPP) calculated using the lists of bipartitions obtained from Bayesian analyses of the eight datasets. The third value is the index of reproducibility (Rep), which is the ratio of the number of datasets supporting the node of interest to the total number of datasets. The MPP and Rep values were directly calculated on SuperTRI v. 57. All SuperTRI values were reported on the Bayesian tree obtained from the supermatrix analysis.

\section{Molecular Dating}

Divergence times were estimated with the Bayesian approach implemented in BEAST v. 2.1.3 (Drummond et al. 2012) using either a COI alignment of 33 taxa and $291 \mathrm{nt}$ or a Cytb alignment of 19 taxa and $1140 \mathrm{nt}$. As no calibration point (fossil record or biogeographic event) is available for Tylonycteris, we employed a range of nucleotide substitution rates used for mammals (Arbogast \& Slowinski 1998; Mao et al. 2010). We used a first mutation rate (R1) of 0.015 per site per lineage per Myr with a lower boundary of 0.01 and an upper boundary of 0.02 , a second mutation rate (R2) of $0.02 \pm 0.005$ per site per lineage per Myr and a third mutation rate (R3) of $0.025 \pm 0.005$ per site per lineage per Myr. We tested R1 and R2 for the CO1 dataset, and R2 and R3 for Cytb dataset. We applied a GTR + I + G model of evolution (based on jModelTest) and a relaxed-clock model with an uncorrelated $\log$ normal distribution for substitution rate. Node ages were estimated using a Yule speciation prior and $10^{8}$ generations, with tree sampling every 1000 generations and a burn-in of $25 \%$. Adequacy of chain mixing and MCMC chain convergence were assessed using the ESS values in Tracer v. 1.6 (available in the BEAST package). The chronograms were generated with TreeAnnotator v. 1.8.2 (also available in the BEAST package) and visualized with FigTree v. 1.4.1 (Rambaut 2009).

\section{Morphological analysis}

For the morphological analysis, 62 adult specimens of Tylonycteris spp. were examined (Appendix 1). Besides mass (expressed in grams), the following external measurements were taken from living bats or museum specimens to the nearest $0.1 \mathrm{~mm}$ : forearm length $(\mathrm{FA})$ - from the elbow to the wrist with both joints folded; head and body length (HB) -from the tip of the face/chin to the anus; tail length (Tail) - from the anus to the tip of the tail; ear length (Ear) - from the base of the ear, where it attaches to the head, to the tip of the pinna. Craniodental measurements were taken to the nearest $0.01 \mathrm{~mm}$ with the use of digital calipers under a stereo microscope and included: GLS - greatest length of skull, from 
TU V.T. et al., Phylogeography of Tylonycteris in Southeast Asia

the anterior rim of the alveolus of the $1^{\text {st }}$ upper incisor to the most posteriorly projecting point of the occipital region; CCL - condylo-canine length, from the exoccipital condyle to the most anterior part of the canine; UCI - from the anterior rim of the alveolus of the first upper incisor to the posterior rim of the alveolus of the canine; $\mathrm{CC}$ - greatest width across the upper canines from their labial borders; $\mathrm{M}^{3} \mathrm{M}^{3}$ - greatest width across the crowns of the last upper molars from their labial borders; IC - least width of the interorbital constriction; $\mathrm{MB}$ - greatest distance across the mastoid region; BW - greatest width of the braincase; $\mathrm{CM}^{3}$ - maxillary toothrow length, from the anterior of the upper canine to the posterior of the crown of the $3^{\text {rd }}$ molar; $\mathrm{ML}$ - mandible length, from the anterior rim of the alveolus of the $1^{\text {st }}$ lower incisor to the most posterior part of the condyle; and $\mathrm{CM}_{3}$ - mandibular toothrow length, from the anterior of the lower canine to the posterior of the crown of the $3^{\text {rd }}$ lower molar.

\section{Data analyses}

Bats were classified into six geographic groups on the basis of our molecular results. Two distinct principle component analyses (PCAs) were done on the craniodental characters with PAST (Hammer et al. 2001) and irrespective of sexes: (1) the log-transformed raw measurements to assess an overall size factor (usually PC1; Barlow et al. 1997; Lindenfors et al. 2007) and (2) log-transformed standardized data (raw score/geometric mean) to assess shape factors (Jungers et al. 1995). The statistically significant difference in mean values of craniodental measurements and PC mean scores between different groups were then tested by one-way analysis of variance (ANOVA, $\mathrm{p} \leq 0.05$ ) followed by Turkey HSD post-hoc test for unequal sample sizes (Zar 1999).

\section{Results}

\section{Phylogeographic analyses based on mitochondrial sequences}

\section{Results derived from the analysis of $\mathrm{COI}$ sequences}

We sequenced a COI fragment of $728 \mathrm{nt}$ for 55 individuals of Tylonycteris and three outgroup taxa collected across Indochina and adjacent areas. Five additional COI sequences of $291 \mathrm{nt}$ were also obtained from old specimens collected from Sumatra (Appendix 1). Our sequences were aligned with all other $C O I$ sequences available in the GenBank database, producing a final alignment containing 101 specimens. The Bayesian analyses reconstructed from the two COI alignments of either 728 nt (Fig. 2) or $291 \mathrm{nt}$ (Appendix 3) showed very similar topologies. Both analyses support the monophyly of the genus Tylonycteris $(\mathrm{PP}=1)$. As noted by Huang et al. (2014), one specimen labelled as T. robustula in GenBank (accession number HM914921) appears within the clade containing all sequences of T. pachypus. Examination of the voucher, ZMMU S-186637 held at the Zoological Museum of Moscow State University, indicates that its cranium clearly fits the diagnosis of T. pachypus (S. Kruskop, in litt.) and that it should be relabelled accordingly. Otherwise, our results strongly support the monophyly of both species of Tylonycteris. In the COI trees (Fig. 2; Appendix 3), the T. pachypus clade is further subdivided into three divergent and highly supported geographic subclades $(\mathrm{PP}=1)$ named $\mathrm{Tp} 1$ (Sumatra), Tp2 (southern Indochina) and Tp3 (northern Indochina). A similar phylogeographic pattern is also detected in T. robustula, with three strongly supported geographic subclades named $\operatorname{Tr} 1$ (Sumatra), $\operatorname{Tr} 2$ (southern Indochina + northwestern India + Peninsular Malaysia) and Tr3 (northern Indochina). Within Indochina, the area of separation between the northern and southern Indochinese subclades corresponds to the region located between Vu Quang (Ha Tinh Province, Vietnam) and Ban Houana (Khammouane Province, Laos) for T. pachypus, whereas it corresponds to the region situated between Nam Et (Houaphan Province, Laos) and Vu Quang (Vietnam) for T. robustula (Fig. 1).

\section{Results derived from the analysis of $C y t b$ sequences}

The Bayesian analysis of the newly generated Cytb sequences $(\mathrm{n}=19)$ and those of Tylonycteris downloaded from GenBank $(n=4)$ produced a topology (Fig. 2) similar to those obtained with the COI gene tree, with two exceptions: (1) T. robustula is paraphyletic because one specimen collected 


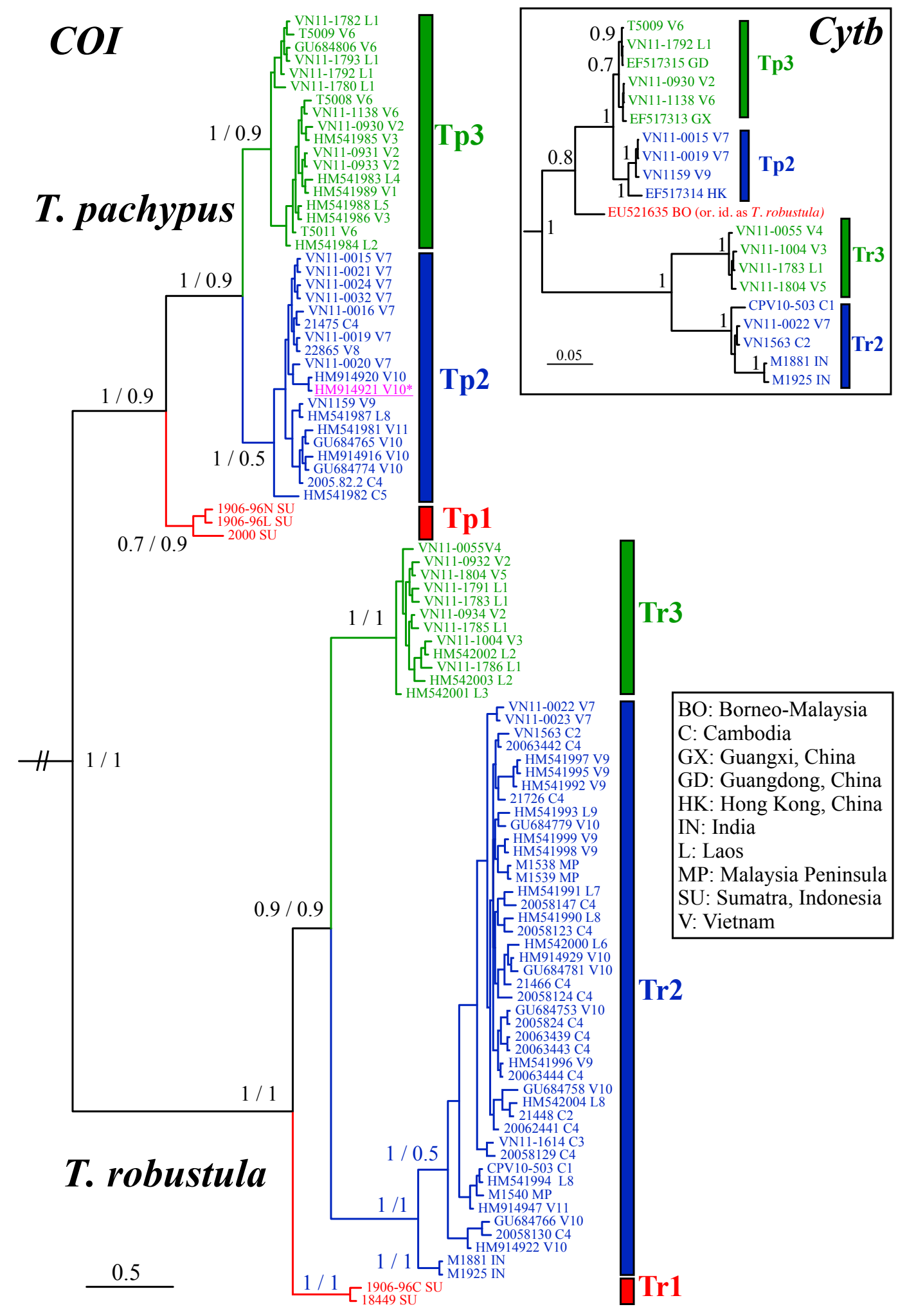

Fig. 2. Bayesian tree obtained from the analyses of $C O I$ and $C y t b$ genes. The values on the nodes indicate posterior probabilities (PP). In the COI tree, PPs were calculated from two DNA alignments of CO1 sequences (728 nt or $291 \mathrm{nt}$; see text for details). The sequence HM914921 was obtained from a specimen originally identified as T. robustula. In the Cytb tree, the sequence EU521635 was obtained from a specimen originally identified as $T$. robustula. 
in Borneo, originally identified as T. robustula (GenBank accession number EU521635; Anrawali et al. unpubl.), appears as sister to the clade containing all T. pachypus specimens $(\mathrm{PP}=0.8)$; and (2) two sequences of T. pachypus from Guangdong and Guangxi (China) are nested within the northern Indochinese subclade (Tp3) of T. pachypus $(\mathrm{PP}=0.7)$ as expected, but a sequence of $T$. pachypus from Hong Kong appears as sister to the southern Indochina subclade (Tp2) $(\mathrm{PP}=1)$ (Fig. 2). These results are consistent with the phylogeographic pattern reported in Huang et al. (2014).

\section{Genetic distances}

The comparisons of interspecific genetic variations, as estimated by $\mathrm{K} 2 \mathrm{P}$ distances, indicate that the specimens from Sumatra differ from those of mainland Southeast Asia by $6.0-6.1 \%$ and $5.7-7.5 \%$ in partial COI sequences (calculated from an alignment of only $291 \mathrm{nt}$ ) for T. pachypus and T. robustula, respectively (Appendix 5). The K2P distances for Cytb sequences (404 nt) between the specimen of T. robustula from Borneo and those representing the Tp2 and Tp3 subclades from Southeast Asia's mainland (Indochina and southern China including Guangdong, Guangxi, and Hong Kong) range from 5.7 to $6.4 \%$. This is significantly smaller than the distance of $12.4-13.8 \%$ measured for other specimens assigned to T. robustula (Appendix 5). Within Indochina, the mean K2P distances inferred from the alignments of COI (728 nt) and Cytb (1140 nt) sequences are $2.8 \%(2.2-3.5 \%)$ and $2.8 \%(2.6-3.0 \%)$ between $\mathrm{Tp} 2$ and $\mathrm{Tp} 3$ of T. pachypus, and 6.5\% (5.5-7.4\%) and 9.5\% (8.6-10.4\%) between $\operatorname{Tr} 2$ and $\operatorname{Tr} 3$ of T. robustula, respectively. The maximal intraspecific distances in Cytb sequences between the specimen from Hong Kong and those from $\operatorname{Tr} 2$ and $\operatorname{Tr} 3$ are 2.0\% and 3.2\% (3.1-3.2\%), respectively (data not shown in Appendix 5).

\section{Supermatrix and SuperTRI analyses of eight independent DNA markers}

The Bayesian trees reconstructed from the concatenation of the seven nuDNA introns ( $5604 \mathrm{nt}$ and 54 indels) or based on the supermatrix of 7526 characters (mtDNA + nuDNA; $7472 \mathrm{nt}$ and 54 indels) are shown in Fig. 3 and Appendix 4, respectively. In the tree of Fig. 3, we report the bootstrap proportions obtained from the ML analyses (Appendix 6), as well as the results of the SuperTRI analyses (SBP, MPP, and Rep, Appendix 7). All these analyses support with maximal values of robustness the monophyly of the genus Tylonycteris and that of the two species, T. pachypus and T. robustula (Fig. 3). Both species can be diagnosed by several indels in the nuclear dataset: 10 for T. pachypus and three for T. robustula (Fig. 3). For instance, all specimens of T. pachypus share a large insertion of ca $250 \mathrm{nt}$ in RIOK3 and a deletion of $47 \mathrm{nt}$ in $H D A C 2$, while a deletion of two bases (CA) in CHPF2 was found in all specimens of $T$. robustula (Fig. 3).

Within T. robustula, the two geographic mtDNA haplogroups corresponding to $\operatorname{Tr} 2$ and $\operatorname{Tr} 3$ in Indochina were recovered with high support values $\left(\mathrm{PP}_{\text {nuDNA }} / \mathrm{PP}_{\text {supermatrix }}=1 ; \mathrm{BP}=100 ; \mathrm{SBP}>95 ; \mathrm{MPP}>0.54\right.$; Rep $>0.5$; Fig. 3). Other relationships within T. robustula are not robust.

Within T. pachypus, no substructure was consistent. The Tp2 subclade was recovered in the supermatrix analyses with modest support and SuperTRI analyses revealed that this node was only supported by the mtDNA dataset. The Tp3 subclade was not found to be monophyletic in supermatrix and superTRI analyses, but the weak support values indicate a lack of resolution rather than real discordance between the datasets.

Interspecific divergences, as estimated from K2P distances, were calculated using the concatenation of the seven nuclear genes (5604 nt). The distances between T. pachypus and T. robustula range from 1.6 to $1.8 \%$. The divergences between specimens of northern and southern Indochina range from 0.4 to $0.6 \%$ for $T$. robustula and from 0 to $0.2 \%$ for $T$. pachypus. The maximum intraspecific variation within each geographical population is $0.2 \%$ for both species (Appendix 5). 


\section{Molecular divergence time estimates}

Our molecular dating estimations based on two different mtDNA alignments (COI and $C y t b)$ and three different rates of substitution (Table 1) suggest that the common ancestor of extant Tylonycteris spp. was already present during the Pliocene epoch (6.56-3.84 Mya), and that the diversification of major geographic clades within both $T$. pachypus and T. robustula occurred during the Early Pleistocene.

\section{Morphological comparisons}

Most craniodental measurements of available T. pachypus specimens are significantly smaller than those of T. robustula (ANOVA, $\mathrm{p} \leq 0.05$ ); whereas those of the three molecular groups within each taxon are overlapping (Table 2). This is reflected in univariate variation of GLS measurements (Fig. 4A) or on the multivariate component of $\mathrm{PC}^{*} 1$ based on raw data. This component accounted for $86.9 \%$ of total variance and was correlated positively with all characters (Table 3), confirming that it represents an overall size factor (Fig. 4B). The range of $\mathrm{PC}^{*} 1$ scores of T. pachypus (between -2.0 and -0.58 ) is significantly smaller than that of $T$. robustula (between -0.38 and 1.33) (ANOVA, $\mathrm{p} \leq 0.05$ ).

The PCA of log-transformed standardized data, which better reflects shape factors, reveals that the two first PCs, PC1 and PC2, accounted for 37.2 and $19.3 \%$ of total variance, respectively (Table 3), with a

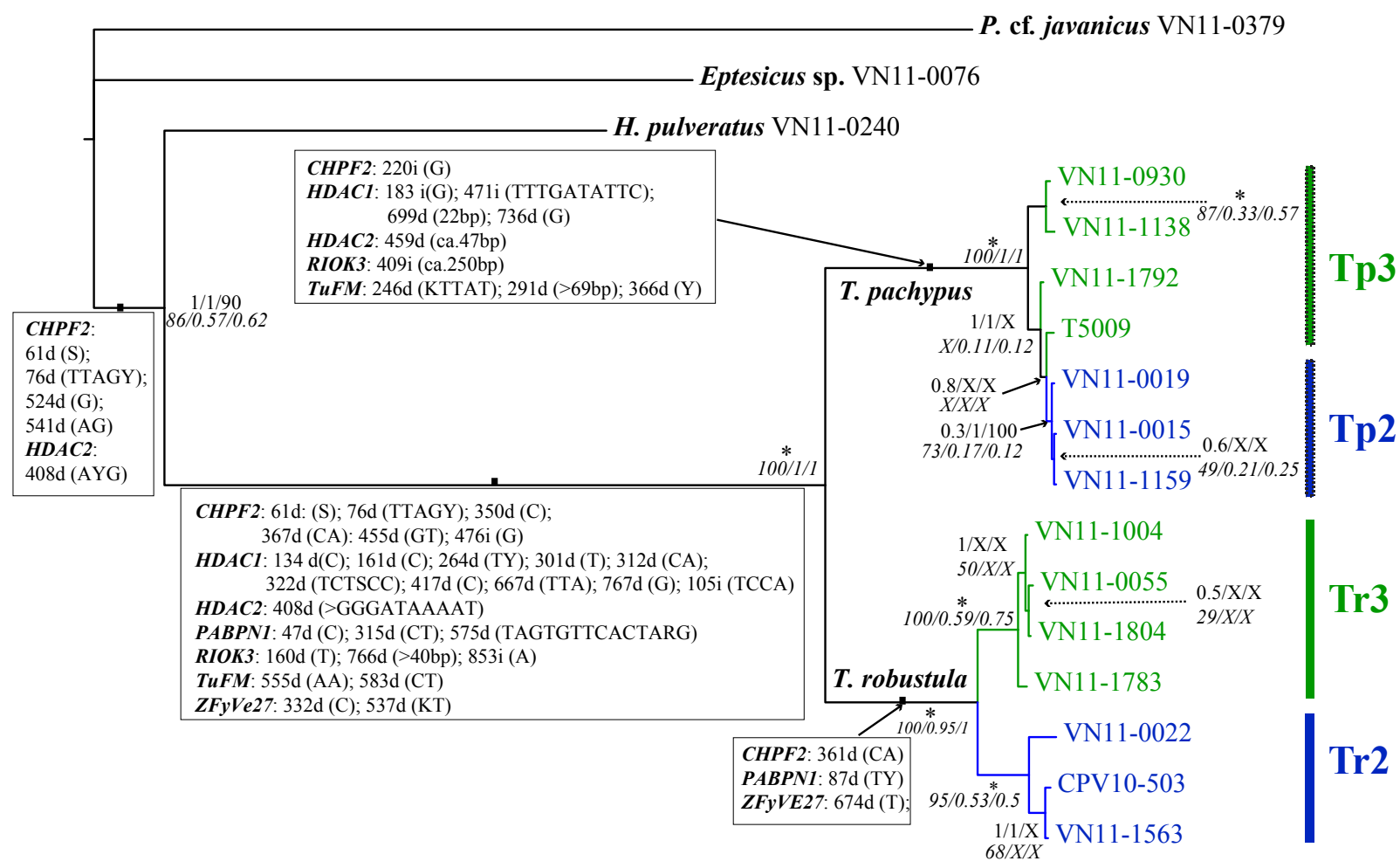

Fig. 3. Bayesian tree reconstructed from the analysis of the seven concatenated nuDNA introns. The seven independent markers are CHPF2 (858 nt), HDAC1 (1128 nt), HDAC2 (639 nt), PABPNI (677 nt), RIOK3 (915 nt), TUFM (655 nt) and ZFYVE27 (732 nt). The values indicated on the branches are the Bayesian posterior probabilities $\left(\mathrm{PP}_{\text {nuDNA }}\right.$ and $\mathrm{PP}_{\text {supermatrix }}$ ), maximum likelihood bootstrap (BP), Supertree Bootstrap percentage (SBP), Mean posterior probability (MPP) and Reproducibility index (Rep). An asterisk indicates that the node was supported by maximal values of robustness $\left(\mathrm{PP}_{\text {nuDNA }}=\mathrm{PP}_{\text {supermatrix }}=1\right.$; $\mathrm{BP}=100$ ). The letter " $\mathrm{X}$ " indicates that the node was not found in the analysis. The position and nature of all diagnostic indels (i: insertion; d: deletion) shared by at least two taxa in the alignments of nuclear genes are indicated in boxes. 
TU V.T. et al., Phylogeography of Tylonycteris in Southeast Asia

Table 1. Bayesian mean node ages in million years ago (Mya) estimated with three different rates of substitution, $0.015 \pm 0.005(\mathrm{R} 1), 0.02 \pm 0.005$ (R2) and $0.025 \pm 0.005$ (R3) per lineage per Myr, and using two different DNA alignements: subunit I of cytochrome $\mathrm{c}$ oxidase $(C O I)$ or cytochrome b $(C y t b)$.

\begin{tabular}{lccccc}
\hline \multicolumn{1}{c}{ Taxa } & COI R1 & COI R2 & Cytb R2 & Cytb R3 & Epochs \\
\hline Tylonycteris & 5.27 & 3.84 & 6.56 & 5.27 & Pliocene \\
T. robustula & 3.07 & 2.22 & NA & NA & E Pleist. \\
Indochina & 2.36 & 1.70 & 2.97 & 2.38 & E Pleist. \\
Northern Indochina & 0.90 & 0.65 & 0.26 & 0.21 & M Pleist. \\
Southern Indochina & 1.38 & 1.00 & 0.48 & 0.39 & E/M Pleist. \\
Sumatra & 0.27 & 0.20 & NA & NA & M Pleist. \\
T. pachypus & 2.70 & 1.96 & 2.44 & 1.96 & E Pleist. \\
Indochina & 1.35 & 0.99 & 0.98 & 0.79 & E/M Pleist. \\
Northern Indochina & 0.45 & 0.33 & 0.25 & 0.20 & M/L Pleist. \\
Southern Indochina + HK & NA & NA & 0.54 & 0.43 & M Pleist. \\
Southern Indochina & 0.71 & 0.52 & 0.12 & 0.10 & M/L Pleist. \\
Sumatra & 0.73 & 0.53 & NA & NA & M Pleist. \\
\hline
\end{tabular}

Abbreviations: HK = Hong Kong; NA = not applicable; Pleist. = Pleistocene; E = Early; $\mathrm{M}=$ Middle; $\mathrm{L}=$ Late.

significant difference in shape components between Tylonycteris taxa (ANOVA, $\mathrm{p} \leq 0.05$ ). In the plot of PC1 against PC2 (Fig. 4C), we found an overlap between T. pachypus and T. robustula. However, this multivariate projection also shows that, within T. pachypus, bats of Tp1 form a cluster clearly separated from bats of Tp2 and Tp3. Within T. robustula, morphological overlap between haplogroups is more extensive, but most $\operatorname{Tr} 2$ individuals tend to separate from $\operatorname{Tr} 1$ and $\operatorname{Tr} 3$ ones.

\section{Systematics of the genus Tylonycteris}

In earlier taxonomic accounts (e.g., Tate 1942 or Medway 1973), the three distinct species T. fulvida (sometimes incorrectly referred to as rubidus) (type locality [t.1.]: Schwe Gyen, Myanmar), T. meyeri Peters, 1872 (t.1.: South Luzon) and T. aurex Thomas, 1951 (t.1.: Astoli, south of Mumbai, India) were treated as subspecies of T. pachypus (t.1.: Java), while T. malayana Chasen, 1940 (t.1.: Peninsular Malaysia) was considered as a subspecies of T. robustula (t.1.: Borneo). Most subsequent authors followed these taxonomic recommendations (Corbet \& Hill 1992; Simmons 2005; Bates et al. 2008a, 2008b; Francis 2008). Previous karyological and genetic data (Francis et al. 2010; Huang et al. 2011) and our new phylogenetic analyses, however, support a clear division between populations of Tylonycteris spp. from mainland Southeast Asia vs those of the Sundaic islands, such as Sumatra and Borneo. We propose therefore to restrict the species names T. pachypus and T. robustula to populations from the Sundaland, where the type specimens were collected (Fig. 1), and to revalidate the following two species names previously used for populations occurring in mainland Southeast Asia (Tate 1942; Medway 1973): the first is T. fulvida, which was originally described as Scotophilus fulvidus from Sittang River (Myanmar) and should be applied to continental bats of the T. pachypus complex; the second is T. malayana, which was originally described from Perak (Peninsular Malaysia) and should be applied to populations of the T. robustula complex found in Peninsular Malaysia, southern Indochina, and northern India. In contrast, all bats of the T. robustula species complex endemic to northern Indochina should be included in the new species described below. Representatives from other isolated populations, notably from the Philippines and the Western Ghats in India would need further scrutiny to assess their taxonomic rank, but certainly represent further distinct taxa. 


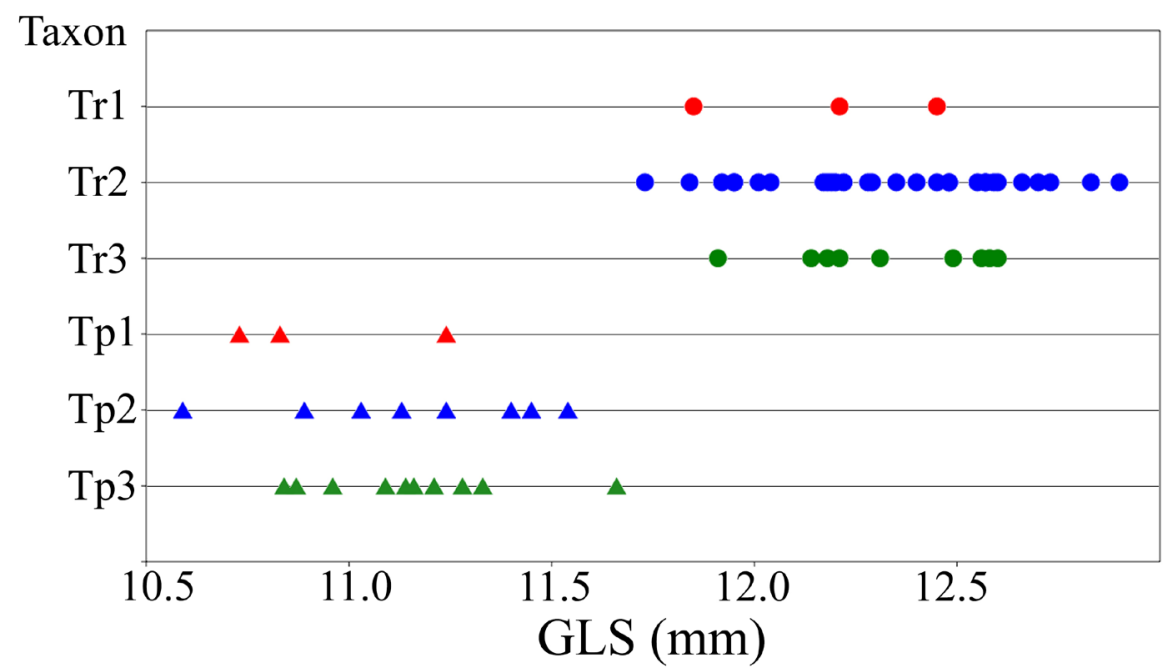

\section{A}

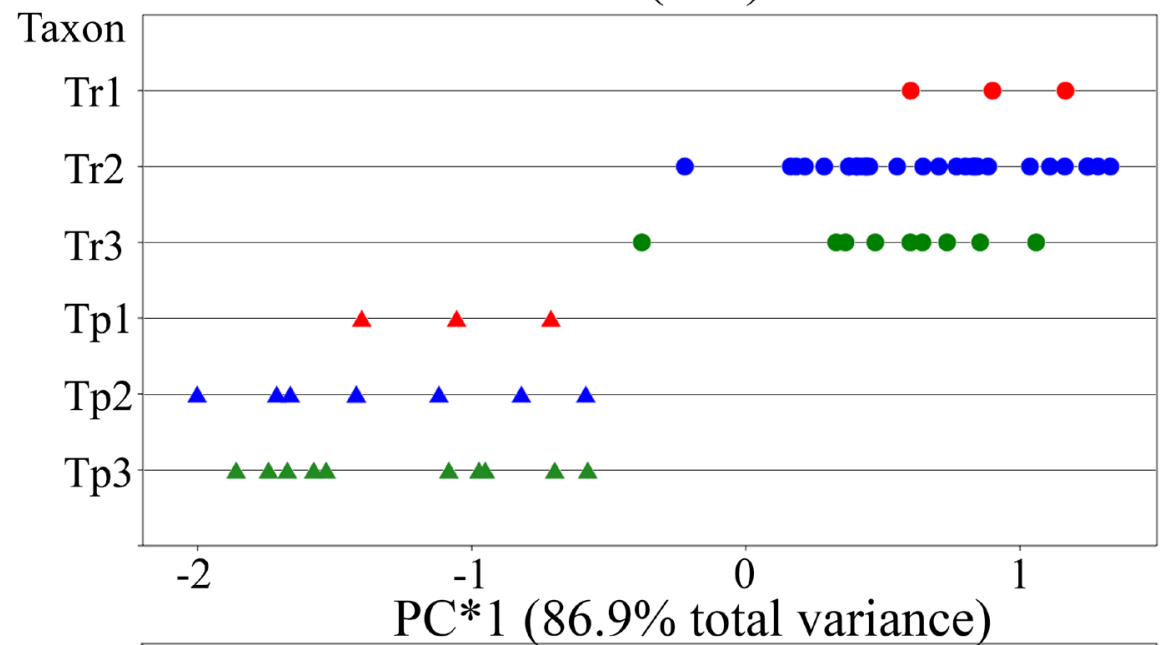

B

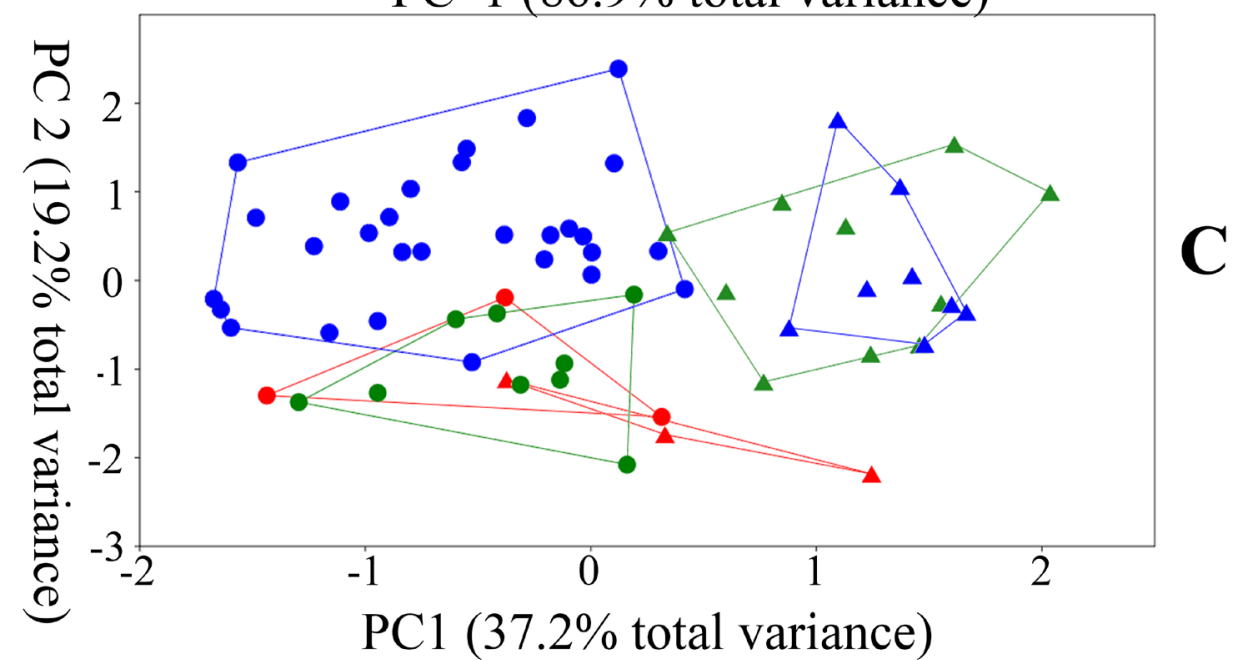

Fig. 4. Scatter plots obtained from morphological analyses of Tylonycteris spp. A. Range of GLS measurements of specimens within each group of Tylonycteris spp. B. Range of PC*1 scores of specimens of Tylonycteris spp. obtained from PCA of log-transformed raw data of craniodental measurements. C. Plot of PC 1 against PC 2 obtained from PCA on log-transformed standardized data. Triangles and circles refer to $T$. pachypus s. lat. and $T$. robustula s. lat., respectively. Colour patterns indicate the mtDNA haplogroups: green for $\operatorname{Tp} 3$ and $\operatorname{Tr} 3$ (northern Indochina); blue for $\operatorname{Tp} 2$ and $\operatorname{Tr} 2$ (other regions of the Southeast Asian mainland); red for Tp1 and Tr1 (Sundaland). 
TU V.T. et al., Phylogeography of Tylonycteris in Southeast Asia

Table 2. Selected external and craniodental measurements (in $\mathrm{mm}$ ) of Tylonycteris spp. Values are given as mean, standard deviation (SD), (n) and min-max. Acronyms and definitions for measurements are given in Material and methods.

\begin{tabular}{|c|c|c|c|c|c|c|}
\hline \multirow[b]{2}{*}{ Character } & \multicolumn{3}{|c|}{ T. pachypus } & \multicolumn{3}{|c|}{ T. robustula } \\
\hline & Tp1 $(\mathrm{n}=3)$ & Tp2 $(\mathrm{n}=8)$ & $\mathbf{T p 3}(\mathrm{n}=10)$ & $\operatorname{Tr} 1(\mathrm{n}=3)$ & $\operatorname{Tr} 2(n=29)$ & $\operatorname{Tr} 3(n=9)$ \\
\hline FA & - & $\begin{array}{c}24.9,0.4(6) \\
24.4-26.4\end{array}$ & $\begin{array}{c}25.7,0.6(7) \\
24.1-25.3\end{array}$ & - & $\begin{array}{c}26.4,0.5(6) \\
25.5-27.5\end{array}$ & $\begin{array}{c}26.7,1.1(5) \\
25.1-27.8\end{array}$ \\
\hline GLS & $\begin{array}{c}10.93,0.27 \\
10.73-11.24\end{array}$ & $\begin{array}{c}11.16,0.32 \\
10.59-11.54\end{array}$ & $\begin{array}{c}11.15,0.24 \\
10.84-11.66\end{array}$ & $\begin{array}{c}12.17,0.30 \\
11.85-12.45\end{array}$ & $\begin{array}{c}12.34,0.31 \\
11.73-12.90\end{array}$ & $\begin{array}{c}12.33,0.24 \\
11.91-12.60\end{array}$ \\
\hline $\mathrm{CCL}$ & $\begin{array}{c}10.19,0.21 \\
10.00-10.41\end{array}$ & $\begin{array}{l}10.26,0.28 \\
9.72-10.69\end{array}$ & $\begin{array}{l}10.25,0.18 \\
9.99-10.54\end{array}$ & $\begin{array}{c}11.36,0.26 \\
11.08-11.59\end{array}$ & $\begin{array}{c}11.23,0.28 \\
10.66-11.82\end{array}$ & $\begin{array}{c}11.29,0.24 \\
10.82-11.62\end{array}$ \\
\hline $\mathrm{CC}$ & $\begin{array}{l}3.57,0.13 \\
3.43-3.68\end{array}$ & $\begin{array}{l}3.51,0.13 \\
3.27-3.67\end{array}$ & $\begin{array}{l}3.52,0.11 \\
3.29-3.69\end{array}$ & $\begin{array}{l}4.12,0.11 \\
4.00-4.21\end{array}$ & $\begin{array}{l}4.09,0.16 \\
3.81-4.46\end{array}$ & $\begin{array}{l}3.92,0.16 \\
3.60-4.12\end{array}$ \\
\hline UCI & $\begin{array}{l}1.81,0.10 \\
1.70-1.88\end{array}$ & $\begin{array}{l}1.66,0.04 \\
1.62-1.76\end{array}$ & $\begin{array}{l}1.66,0.08 \\
1.52-1.79\end{array}$ & $\begin{array}{l}2.04,0.06 \\
1.98-2.10\end{array}$ & $\begin{array}{l}1.98,0.10 \\
1.77-2.17\end{array}$ & $\begin{array}{l}1.98,0.08 \\
1.86-2.10\end{array}$ \\
\hline $\mathrm{M}^{3} \mathrm{M}^{3}$ & $\begin{array}{l}4.74,0.08 \\
4.65-4.80\end{array}$ & $\begin{array}{l}4.86,0.20 \\
4.62-5.15\end{array}$ & $\begin{array}{l}4.91,0.21 \\
4.48-5.24\end{array}$ & $\begin{array}{l}5.67,0.17 \\
5.53-5.86\end{array}$ & $\begin{array}{l}5.54,0.20 \\
5.13-5.90\end{array}$ & $\begin{array}{l}5.47,0.14 \\
5.28-5.76\end{array}$ \\
\hline IC & $\begin{array}{l}3.46,0.08 \\
3.37-3.51\end{array}$ & $\begin{array}{l}3.28,0.10 \\
3.16-3.42\end{array}$ & $\begin{array}{l}3.33,0.21 \\
3.02-3.72\end{array}$ & $\begin{array}{l}3.97,0.09 \\
3.90-4.08\end{array}$ & $\begin{array}{l}3.76,0.14 \\
3.52-4.01\end{array}$ & $\begin{array}{l}3.90,0.19 \\
3.48-4.11\end{array}$ \\
\hline MB & $\begin{array}{l}7.08,0.07 \\
7.00-7.14\end{array}$ & $\begin{array}{l}7.02,0.25 \\
6.59-7.38\end{array}$ & $\begin{array}{l}6.85,0.16 \\
6.52-7.04\end{array}$ & $\begin{array}{l}7.70,0.33 \\
7.32-7.89\end{array}$ & $\begin{array}{l}7.43,0.18 \\
7.14-7.80\end{array}$ & $\begin{array}{l}7.34,0.17 \\
7.04-7.54\end{array}$ \\
\hline BW & $\begin{array}{l}6.49,0.14 \\
6.33-6.58\end{array}$ & $\begin{array}{l}6.29,0.15 \\
6.00-6.51\end{array}$ & $\begin{array}{l}6.40,0.26 \\
6.14-6.83\end{array}$ & $\begin{array}{l}7.10,0.27 \\
6.80-7.29\end{array}$ & $\begin{array}{l}6.78,0.21 \\
6.40-7.36\end{array}$ & $\begin{array}{l}6.88,0.34 \\
6.54-7.50\end{array}$ \\
\hline $\mathrm{CM}^{3}$ & $\begin{array}{l}3.50,0.15 \\
3.37-3.66\end{array}$ & $\begin{array}{l}3.48,0.16 \\
3.27-3.73\end{array}$ & $\begin{array}{l}3.54,0.14 \\
3.33-3.79\end{array}$ & $\begin{array}{l}4.05,0.10 \\
3.98-4.17\end{array}$ & $\begin{array}{l}4.06,0.12 \\
3.74-4.31\end{array}$ & $\begin{array}{l}3.96,0.10 \\
3.81-4.12\end{array}$ \\
\hline ML & $\begin{array}{l}7.77,0.19 \\
7.56-7.93\end{array}$ & $\begin{array}{l}7.79,0.35 \\
7.38-8.32\end{array}$ & $\begin{array}{l}7.81,0.24 \\
7.41-8.13\end{array}$ & $\begin{array}{l}8.56,0.16 \\
8.41-8.73\end{array}$ & $\begin{array}{l}8.71,0.23 \\
8.25-9.19\end{array}$ & $\begin{array}{l}8.59,0.25 \\
8.08-8.99\end{array}$ \\
\hline $\mathrm{CM}_{3}$ & $\begin{array}{l}3.78,0.13 \\
3.65-3.90\end{array}$ & $\begin{array}{l}3.74,0.21 \\
3.51-4.09\end{array}$ & $\begin{array}{l}3.76,0.17 \\
3.51-4.03\end{array}$ & $\begin{array}{l}4.26,0.14 \\
4.18-4.43\end{array}$ & $\begin{array}{l}4.32,0.13 \\
4.08-4.53\end{array}$ & $\begin{array}{l}4.16,0.15 \\
3.92-4.47\end{array}$ \\
\hline
\end{tabular}

Phylum Chordata Haeckel, 1874

Class Mammalia Linnaeus, 1758

Order Chiroptera Blumenbach, 1779

Family Vespertilionidae Gray, 1821

Subfamily Vespertilioninae Gray, 1821

Tylonycteris tonkinensis $\mathrm{Tu}$, Csorba, Ruedi \& Hassanin sp. nov. urn:Isid:zoobank.org:act:C59B0774-79D6-4A84-9489-CF04BE35FC49

Fig. 5B

Tylonycteris robustula Thomas, 1915 (partim): 227.

Tylonycteris robustula - Osgood 1932: 236. — Tate 1942: 268. — Hendrichsen et al. 2001: 90. Kruskop 2013: 221. — Thomas et al. 2013: 229.

\section{Etymology}

The specific epithet refers to the current restricted occurrence of the new species in north-eastern Laos and northern Vietnam (Fig. 1). The Vietnamese portion of this region was previously called "Tonkin" 
Table 3. Factor loadings of craniodental characters for the PCs obtained from principle component analyses (PCAs) of specimens of Tylonycteris. Acronyms and definitions for measurements are given in Material and methods. The first PCA is based on raw data (PC*1), while the second PCA is based on the log-transformed, standardized data (PC1 and PC2). Values in bold indicate the most significant loadings.

\begin{tabular}{cccc}
\hline & Raw data & \multicolumn{2}{c}{ Standardized data } \\
Characters & PC $^{* 1}$ & PC1 & PC2 \\
\hline GLS & $\mathbf{0 . 2 5}$ & 0.14 & 0.04 \\
CCL & $\mathbf{0 . 2 3}$ & 0.22 & -0.02 \\
CC & $\mathbf{0 . 3 6}$ & -0.18 & 0.25 \\
UCI & $\mathbf{0 . 4 1}$ & $\mathbf{- 0 . 6 2}$ & $\mathbf{- 0 . 3 8}$ \\
$\mathrm{M}^{3} \mathrm{M}^{3}$ & $\mathbf{0 . 3 2}$ & -0.02 & 0.30 \\
$\mathrm{IC}$ & $\mathbf{0 . 3 4}$ & -0.15 & $\mathbf{- 0 . 6 2}$ \\
$\mathrm{MB}$ & 0.17 & $\mathbf{0 . 4 7}$ & -0.10 \\
$\mathrm{BW}$ & 0.19 & $\mathbf{0 . 4 3}$ & -0.28 \\
$\mathrm{CM}$ & $\mathbf{0 . 3 5}$ & -0.22 & 0.29 \\
$\mathrm{ML}$ & $\mathbf{0 . 2 7}$ & 0.09 & 0.16 \\
$\mathrm{CM}$ & $\mathbf{0 . 3 4}$ & -0.17 & $\mathbf{0 . 3 5}$ \\
Eigenvalue & 0.0082 & 0.0006 & 0.0003 \\
\% variance & 86.9 & 37.2 & 19.3 \\
\hline
\end{tabular}

during the Nguyễn dynasty and French colonial era (from the $19^{\text {th }}$ to the mid-20 $0^{\text {th }}$ centuries) to separate it from the country's centre (Annam) and southern regions (Cochinchina). The proposed English name is "Tonkin's greater bamboo bat" and the proposed Vietnamese name is 'Dơi ống tre Bắc Bộ'.

\section{Type material}

\section{Holotype}

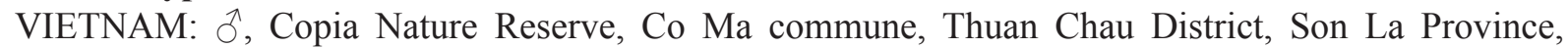
$21^{\circ} 21.727^{\prime} \mathrm{N}, 103^{\circ} 30.562^{\prime} \mathrm{E}, 1286 \mathrm{~m}$ a.s.1., 9 May 2011, Vuong Tan Tu leg. (IEBR-VN11-0055; field number Tu.090511.3; tissue code VN11-0055). Body in alcohol, skull removed. Mass: $4 \mathrm{~g}$. Measurements (in mm): FA: 27.0; HB: 41.0; Tail: 33.0; Ear: 11.0; GLS: 12.60; CCL: 11.59; UCI: 1.98; CC: 4.06; $\mathrm{M}^{3} \mathrm{M}^{3}$ : 5.46; IC: 3.97; MB: 7.42; BW: 7.07; $\mathrm{CM}^{3}: 3.96$; $\mathrm{ML}: 8.64 ; \mathrm{CM}_{3}: 4.22$. Accession numbers of mitochondrial and nuclear sequences: KX496422-KX496429.

\section{Paratypes}

LAOS: 3 adult $\widehat{\partial} \widehat{\partial}$ (MHNG 1926.059, MNHN 2006-90, MNHN 2006-93), 1 adult $q$ (MHNG 1926.057), Hat Hin, Nam Sing River, Phongsaly Province, $21^{\circ} 40.14^{\prime}$ N, $102^{\circ} 13.26^{\prime}$ E, 2004, Manuel Ruedi leg., body in alcohol, skull removed.

VIETNAM: $1 \partial^{\Uparrow}$ (IEBR-VN11-1804), Hang Kia, Pa Co Nature Reserve, Hoa Binh Province, $20^{\circ} 44.910^{\prime} \mathrm{N}$, $104^{\circ} 54.900^{\prime}$ E, $1080 \mathrm{~m}$ a.s.1., 2012, Vuong Tan Tu leg., body in alcohol, skull removed.

Accession numbers of DNA sequences for paratypes are given in Appendix 1.

\section{Referred material}

Specimens identified as T. robustula collected from Na Don, Phuong Vien, Cho Don (Bac Kan Province) and Na Hang Nature Reserve (Tuyen Quang Province) (Appendix 1) are also referred to T. tonkinensis sp. nov. 


\section{Description}

A member of the T. robustula species complex comprising representatives of the $\operatorname{Tr} 3$ haplogroup found in northern Indochina. Externally, individuals are small, with a forearm length of 25.1-27.8 mm (Table 2). The head is dorsoventrally very flattened. Pelage coloration is relatively variable, more or less golden red at the base of the dorsal fur, to dark brown near the tips of the dorsal hairs, and lighter golden brown on the underparts (Fig. 5B). The ears have a triangular shape, with broadly rounded tips. The tragus is short and blunt. The wing membranes are dark brown. The base of thumbs and soles of hind feet have fleshy pads (Fig. 5B).

The skull is small (GLS: 11.91-12.60 mm), lightly built and very flat (Fig. 5B). The rostrum is short. The sagittal crest is absent. The lambdoid crests are well developed. The dental formula is $\mathrm{I} 2 / 3 \mathrm{C} 1 / 1, \mathrm{P} 1 / 2$, $\mathrm{M} 3 / 3=32$. The first upper incisor $\left(\mathrm{I}^{2}\right)$ is bicuspidate, with small cusps on cingulum. $\mathrm{I}^{3}$ is unicuspidate, about half the height and crown area of $\mathrm{I}^{2}$. The upper canine has a posterior supplementary cusp. A diastema between $\mathrm{I}^{3}$ and the upper canine is clearly visible. The protocones of $\mathrm{M}^{1}$ and $\mathrm{M}^{2}$ are welldeveloped. $\mathrm{M}^{2}$ appreciably exceeds $\mathrm{M}^{1}$ in width, and its width clearly exceeds its length. $\mathrm{M}^{3}$ is relatively smaller and without a metastyle. The three lower incisors are tricuspidate. The first $\left(\mathrm{PM}_{2}\right)$ and second $\left(\mathrm{PM}_{4}\right)$ premolars are approximately equal in height and crown area (Fig. 5B).

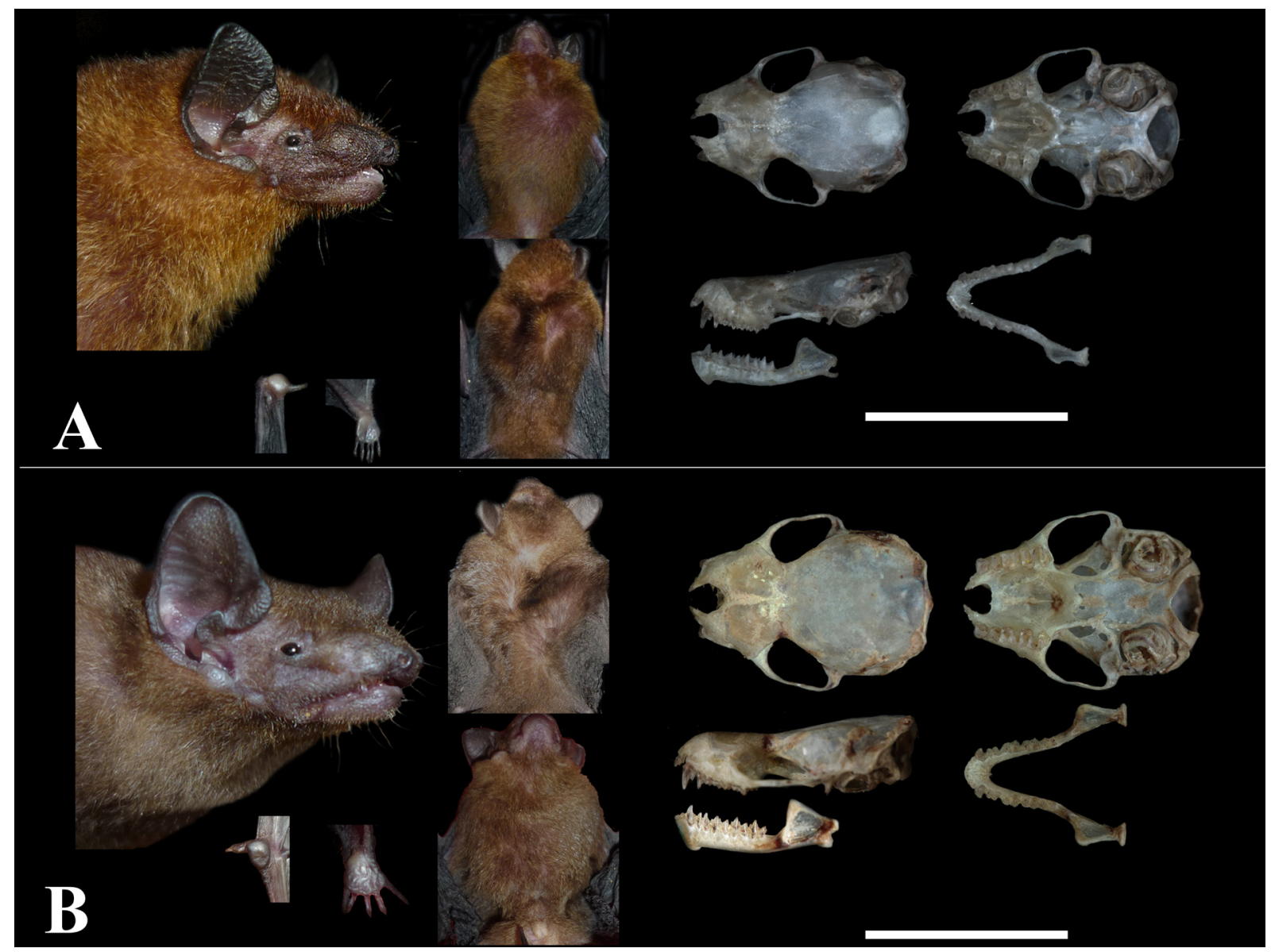

Fig. 5. Morphological characteristics of the two nominal species of the genus Tylonycteris Peters, 1872. A. T. pachypus (Temminck, 1840) (corrected taxon name is T. fulvida (Blyth, 1859)), IEBR-VN110015. B. T. robustula Thomas, 1915 (corrected taxon name is T. tonkinensis Tu, Csorba, Ruedi \& Hassanin sp. nov.), holotype, IEBR-VN11-0055. Head profiles, ventral and dorsal views, fleshy pads at the base of the thumb and on the sole of the foot, and different views of the skull (dorsal, ventral and lateral). Scale $=10 \mathrm{~mm}$. 


\section{Remarks}

In northern Indochina, T. tonkinensis sp. nov. can be distinguished from T. fulvida and T. pygmaea by its significantly larger body and skull size (Table 2; Figs 4-5; see Feng et al. 2008 for comparisons with T. pygmaea), by K2P distances of at least $12 \%$ for $C y t b$ and $C O I$ sequences and by K2P distances of at least $1.5 \%$ for the concatenation of the seven nuclear genes (5604 nt) (Appendix 5). Within the T. robustula complex, $T$. tonkinensis sp. nov. is morphologically overlapping with $T$. robustula, found in Sumatra, and T. malayana ( $=\operatorname{Tr} 2$ haplogroup), collected from the Southeast Asian mainland, but differs from the first taxon by K2P distances of at least 5.2\% in COI sequences (Appendix 5) and from the latter by K2P distances of at least 5.5\%, 8.6\% and $0.4 \%$ calculated from COI sequences ( $657 \mathrm{nt}$ ), Cytb sequences (1140 nt) and the concatenation of seven nuclear DNA sequences (5604 nt), respectively (Appendix 5).

\section{Ecology and habitat}

Like other species of Tylonycteris, T. tonkinensis sp. nov. is associated with woody bamboo groves. The new species is usually found in sympatry with the smaller species T. fulvida (Fig. 1). In northwestern Vietnam, bats of the new species were captured in mist-nests set near bamboo groves in forest edges adjacent to rural-residential areas at relatively high elevations, e.g., at 1010 m a.s.l in Hang Kia, Pa Co Nature Reserve (Hoa Binh Province) or at $1286 \mathrm{~m}$ a.s.l in its type locality. In Laos, the known localities are found at lower elevations, between 500 and $800 \mathrm{~m}$ a.s.l.

\section{Distribution}

Currently, the new species is known to occur in north-eastern Laos and northern Vietnam only (Fig. 1).

\section{Discussion}

\section{Cryptic species diversity in the genus Tylonycteris}

Previous studies have detected high levels of genetic and karyological variation among specimens identified as either T. pachypus or T. robustula collected from different geographic locations in mainland Southeast Asia (Francis et al. 2010; Huang et al. 2014). Our COI analyses further revealed the existence of three divergent geographic haplogroups for both T. pachypus and T. robustula, for each corresponding to Sumatra, northern Indochina and southern Indochina (but also northwestern India and Peninsular Malaysia for T. robustula). Our Cytb dataset confirmed the existence of these geographic haplogroups in mainland Southeast Asia. In addition, a specimen of T. pachypus collected from Borneo and originally described as T. robustula was found to be highly divergent from the two other Indochinese haplogroups (Fig. 2). In the absence of $C y t b$ data for Sumatran specimens, it is impossible to know whether they share the same mitochondrial lineage as those from Borneo.

Taken together, our mtDNA analyses show that all haplotypes sequenced for insular Tylonycteris are very divergent from those identified in mainland Southeast Asia. However, genetic inferences based on the maternally inherited mitochondrial genes are prone to be discordant with the true evolutionary history of the taxa, owing to various evolutionary processes, such as mtDNA introgression, incomplete lineage sorting or female philopatry (Avise 2000; Ballard \& Whitlock 2004; Hassanin \& Ropiquet 2007; Nesi et al. 2011; Rivers et al. 2005). Here, the geographic pattern of mtDNA diversity observed for the two species of Tylonycteris could be the consequence of female philopatry, i.e., the behavior of remaining in, or returning to the natal territory. Indeed, bat species with philopatric females generally display high geographic structure when relationships are examined with maternally inherited markers, such as the mitochondrial DNA. This pattern can disappear with biparentally inherited markers when adult males are able to disperse over long distances, allowing gene flow between otherwise isolated populations (Castella et al. 2001; Hassanin et al. 2015; Hulva et al. 2010; Pereira et al. 2009; Rivers 
et al. 2005). Behavioral and population genetic studies in southern China have shown that T. pachypus bats are philopatric to their natal area and that philopatry is especially pronounced in females (Hua et al. 2011, 2013). Although no data are available for T. robustula, female philopatry can also be predicted for this species, because it shares similar morphological, behavioural and ecological traits with $T$. pachypus (Medway 1972; Medway \& Marshall 1970, 1972; Zhang et al. 2007). The social organization of T. pachypus and T. robustula, combined with their fragmented habitats, is therefore expected to result in limited gene flow between populations, especially among matrilines from distant geographic localities. For both species, this prediction is corroborated by the analyses of mtDNA markers, with the identification of three divergent geographically non-overlapping haplogroups. For T. robustula, this phylogeographic pattern is also supported by the nuclear sequence data, as the two Indochinese clades were recovered monophyletic with all the three introns containing enough nucleotide variation at the intra-specific level, i.e., CHPF2, HDAC1 and TUFM (Appendix 8). By contrast, our nuclear analyses (Fig. 3; Appendices 4, 8) do not support the reciprocal monophyly of the two Indochinese clades of T. pachypus, suggesting that gene flow was maintained by male dispersal or, alternatively, that their separation was too recent to be detected with our nuclear genes.

Nucleotide distances estimated from mtDNA genes between northern and southern Indochinese populations of T. robustula were more than twice those of T. pachypus (6.5\% vs $2.8 \%$ in COI; $9.5 \%$ vs $2.8 \%$ in $C y t b$ ), indeed supporting a more recent divergence for the latter taxon, if we assume equal evolutionary rates. Similarly, the nuclear distances between the two Indochinese clades of T. robustula were between 0.41 and $0.56 \%$, which is more than twice those calculated between Indochinese individuals of T. pachypus (0-0.2\%; Appendix 5) and in the range of interspecific distances found in other groups of Laurasiatheria, such as fruit bats of the tribes Myonycterini (Nesi et al. 2013) and Scotonycterini (Hassanin et al. 2015), or cattle and buffalo of the tribe Bovini (Hassanin et al. 2013). Although none of the nuclear markers could be sequenced for Sumatran and Bornean Tylonycteris, their high mtDNA divergence from Indochinese populations ( $>5.7 \%$ in both COI and Cytb sequences; Appendix 5) suggests they might represent distinct lineages based on nuclear markers as well. In agreement with this view, our multivariate morphological analyses revealed that Indochinese bats of the T. pachypus complex constitute a distinct group separated from those collected on Sumatra. For the T. robustula complex, morphological overlap between haplogroups is more extensive, but pairwise comparisons of their PC mean scores support the distinctness of adjacent geographical taxa, such as $\operatorname{Tr} 2$ and $\operatorname{Tr} 3$ on the Southeast Asian mainland.

The close morphological similarity among taxa of Tylonycteris suggests that they have evolved under the influences of similar and specialized habitats, i.e., woody bamboo vegetation. Molecular evidence indicates, however, that T. pachypus should be split into at least two distinct species, T. pachypus on the Sunda islands (Sumatra and/or Borneo) and T. fulvida in mainland Southeast Asia, and that T. robustula should be divided into at least three species, with T. robustula on Sumatra, T. malayana in southern and western mainland Southeast Asia, and T. tonkinensis sp. nov. in northern Indochina.

\section{The evolution of Tylonyteris spp. in Southeast Asia during the Pleistocene}

Given that both species complexes, here named T. pachypus s. lat. and T. robustula s. lat., are usually found in sympatry across most of their geographic ranges in Southeast Asia, they are expected to share a common phylogeographical history. Our estimates of divergence times based on mtDNA sequences suggest that the genus Tylonycteris diversified during the Pliocene epoch (Cytb: $5.92 \pm 0.65$ Mya; COI: $4.56 \pm 0.72 \mathrm{Mya}$ ) (Table 1). During the Miocene and until the early Pliocene, Southeast Asia was generally covered by large tracks of rain forests as a consequence of warm and humid climatic conditions (Meijaard \& Groves 2006; Morley 2000). Thus, ancestors of both Tylonycteris species complexes were presumably widely distributed across Southeast Asia during the Pliocene. 
Our molecular dating estimates indicate that the basal geographic splits within the two species complexes, i.e., between mainland Southeast Asia and Sumatra, took place approximately at the same time during the Early Pleistocene (between 2.70 and 1.96 Mya for T. pachypus, between 3.07 and 2.22 Mya for T. robustula; Table 1). The Pleistocene epoch is characterized by the onset of repeated cycles of cold glacial and warm interglacial periods as the results of the glaciations/deglaciations of the Northern Hemisphere, which implied contraction and expansion of rain forests in Asia (An et al. 2001; Meijaard \& Groves 2006; Morley 2000). As bats of the genus Tylonycteris are highly dependent on woody bamboo vegetation for roosting, foraging and mating (Kunz 1982; Medway 1972; Medway \& Marshall 1970, 1972), their Pleistocene biogeographic history was firmly constrained by the distribution of such bamboo habitats. The current distribution of woody bamboo species in Asia (Bystriakova et al. 2003b; Fig. 6) indicates that eight disjunctive biogeographic regions have higher species richness ( $>5$ species) for some bamboo genera: southern India (Ochlandra Thwaites), northern Myanmar (Cephalostachyum Munro), southern China (Dendrocalamus Nees and Bambusa Schreb.), Hainan Island (Bambusa), northwestern Thailand (Dendrocalamus and Gigantochloa Kurz ex Munro), Peninsular Malaysia (Gigantochloa), Sumatra and Borneo (Gigantochloa and Schizostachyum Nees). All these regions may therefore have acted as distinct bamboo forest refugia during the glacial periods of the Pleistocene (Fig. 6). Evidence for a number of these postulated glacial refugia has been reported in previous studies for many organisms, including bats (Flanders et al. 2011; Khan et al. 2010; Lin et al. 2014; Mao et al. 2013). Accordingly, we propose that the contraction of woody bamboo forests into different glacial refugia had fragmented the distribution of the Pliocene ancestors of both T. pachypus s. lat. and T. robustula $\mathrm{s}$. lat. In addition, we can assume that Pleistocene glacial periods resulted in higher interspecific competition between co-distributed species of Tylonycteris, because the supply of most suitable resources was more limited in glacial bamboo forest refugia (Medway \& Marshall 1970). As noted in previous studies, T. pachypus s. lat. has a more manoeuvrable flight in cluttered habitats and forages on smaller insects than T. robustula s. lat. (Zhang et al. 2005, 2007). Moreover, Medway \& Marshall (1970) found that the smaller T. pachypus s. lat. can roost in the internodes with small entrance holes, which the larger T. robustula $\mathrm{s}$. lat. is unable to enter. These differences suggest, therefore, that the smaller T. pachypus s. lat. have greater advantages than the larger T. robustula $\mathrm{s}$. lat. in interspecific competition when natural resources are limited. Hence, isolated populations of $T$. robustula s. lat. may have been more exposed to bottlenecks and therefore more vulnerable to local extinction than those of co-distributed T. pachypus s. lat.

During interglacial periods of the Early Pleistocene, warmer and humid conditions resulted in the expansion of woody bamboo forests, which in turn may have favored the restoration of connectivity between isolated populations of both complexes. However, the isolated populations may have been connected or not, depending on their dispersal capacity and the distances between refugia. In T. robustula s. lat., these processes may have taken longer, because of its lower population abundance (Lande \& Barrowclough 1987; Shaffer 1981), and may have been prevented in cases of extinction of transitional populations (Huang et al. 2014 and references therein). This scenario is supported by the fact that T. pachypus s. lat. is usually found to be more abundant than T. robustula s. lat. in bamboo forests (Zhang et al. 2004; Medway \& Marshall 1972) and by the wider geographic range of T. pachypus s. lat. (Bates et al. 2008a, 2008b; Fig. 1). Knowing this, the body size differences between the two species complexes may be the key factor explaining why the basal divergence of northern Indochinese populations occurred earlier in T. robustula s. lat. (i.e., T. tonkinensis sp. nov) than in T. pachypus s. lat., i.e., 2.97-1.70 vs 1.35-0.79 Mya (Table 1). During Pleistocene interglacials, exchanges of Tylonycteris spp. between the continent and the islands of Sundaland were probably prevented because of the long distances between the glacial forest refugia, as well as the higher sea levels (Fig. 1). Our molecular dating estimates corroborate this scenario, as continental populations of Tylonycteris spp. from Indochina and Peninsular Malaysia diverged from insular populations (Sumatra and Borneo) in the Early Pleistocene (Table 1). 


\section{Implications for conservation}

Previous studies considered T. pachypus and T. robustula to be common species and thus classified them as Least Concern in the IUCN Red List (Bates et al. 2008a, 2008b). Since our study reveals that both species in fact represent several species with more restricted distributions, the IUCN status of the different taxa should be reassessed urgently, including that of the new species, T. tonkinensis sp. nov. In addition, our study suggests that several biogeographic regions have acted as Pleistocene glacial refugia. This information is very important for developing more effective conservation strategies, particularly
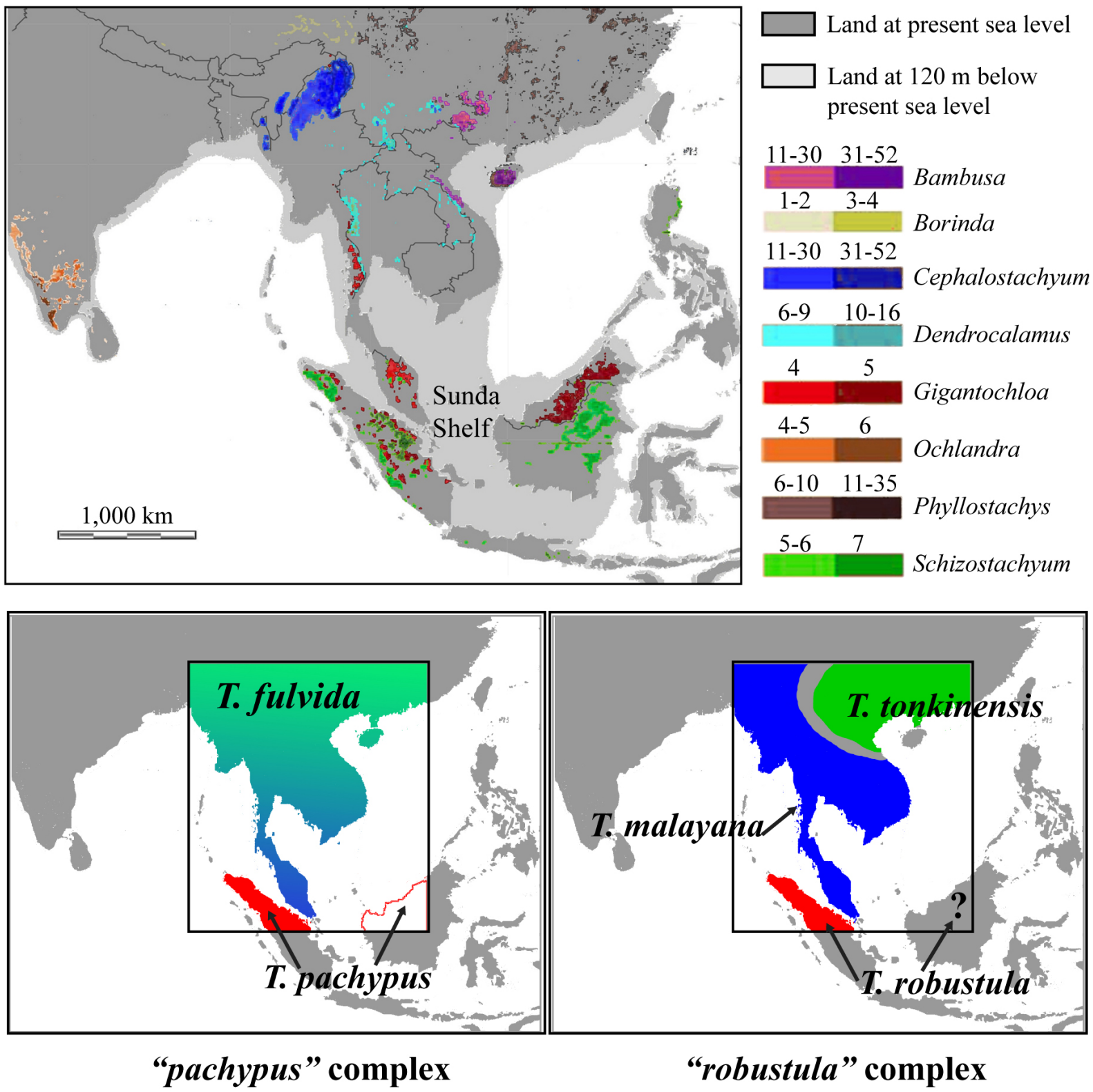

Fig. 6. Distribution and species richness for the eight genera of woody bamboo forests currently found in Asia (adapted and modified from Bystriakova et al. 2003b) and putative geographic range areas of the species of Tylonycteris. During glacial periods of the Pleistocene, the highlighted biogeographic regions may have acted as bamboo refugia for Tylonycteris spp. Moreover, sea level falls (at around $120 \mathrm{~m}$ below present) exposed land bridges, such as the entire Sunda Shelf (adapted from Voris 2000), connecting the islands to the continent. 
given the high current rates of deforestation affecting most natural habitats in Southeast Asia (Kingston 2010; Sodhi et al. 2010; Tordoff et al. 2012).

\section{Acknowledgements}

In Vietnam, we would like to thank P.D. Tien (IEBR), D.Q. Thang and N.X. Nghia (Ngoc Linh NR) and N.T. Son (Vu Quang NP) for their support during the field surveys. We are grateful to L.X. Canh, T.H. Thai, N.V. Sinh and other colleagues of the IEBR, Hanoi for administrative assistance. The field research was done under the permissions of the People's Committees of numerous provinces and the Vietnamese Ministry of Agriculture and Rural Development (Vietnam Administration of Forestry). In Cambodia, we would like to acknowledge T.D. Vong, V. Hul and S. In for their support during the field surveys, and C. Garnero-Morena, G. Diffloth, B. Kilian, A. Beschaouch and N. Hayashi-Denis for their assistance. In Laos, field surveys were realized with the help of R. Kirsch, A. Cibois and J. Fuchs. The field trips were organized by UNESCO under the permissions of the National Authority for Preah Vihear, the President, His Excellency Mr. Chuch Phoeurn and the Director of the Preah Vihear temple, Prof. Hang Soth. We thank collection managers and curators who provided samples from museum specimens: W. van Bohemen and S. van der Mije at the Naturalis Biodiversity Center (Leiden, The Netherlands); and J.-M. Pons and A.M. Ohler at the MNHN (Paris, France). This research was supported by the "ATM Barcode" funded by the MNHN, the "Bibliothèque du Vivant" network funded by the CNRS, the MNHN, the INRA and the CEA (Genoscope), the "Société des Amis du Muséum et du Jardin des Plantes", Rufford Foundation (UK), the SYNTHESYS Project, which is financed by European Community Research Infrastructure Action under the FP7 "Capacities" Program, the Hungarian Scientific Research Fund (OTKA) K112440, the Vietnamese Ministry of Education and Training, the French government (through Campus France Agency and "CROUS de Paris"), and the Leg Prevost of MNHN.

\section{References}

An Z., Kutzbach J.E., Prell W.L. \& Porter S.C. 2001. Evolution of Asian monsoons and phased uplift of the Himalaya-Tibetan plateau since Late Miocene times. Nature 411 (6833): 62-66. http://dx.doi. org/10.1038/35075035

Arbogast B.S. \& Slowinski J.B. 1998. Pleistocene speciation and the mitochondrial DNA clock. Science 282 (5396): e1955. http://dx.doi.org/10.1126/science.282.5396.1955a

Avise J.C. 2000. Phylogeography: The History and Formation of Species. Harvard University Press, Cambridge, Massachusetts.

Ballard J.W.O. \& Whitlock M.C. 2004. The incomplete natural history of mitochondria. Molecular Ecology 13 (4): 729-744. http://dx.doi.org/10.1046/j.1365-294X.2003.02063.x

Barlow K.E., Jones G. \& Barratt E.M. 1997. Can skull morphology be used to predict ecological relationships between bat species? A test using two cryptic species of pipistrelle. Proceedings of the Royal Society B 264 (1388): 1695-1700. http://dx.doi.org/10.1098/rspb.1997.0235

Bates P., Francis C., Rosell-Ambal G., Heaney L., Molur S. \& Srinivasulu C. 2008a. Tylonycteris pachypus. The IUCN Red List of Threatened Species 2008: e.T22577A9377719. http://dx.doi. org/10.2305/IUCN.UK.2008.RLTS.T22577A9377719.en

Bates P., Francis C., Rosell-Ambal G. \& Heaney L. 2008b. Tylonycteris robustula. The IUCN Red List of Threatened Species 2008: e.T22578A9378011. http://dx.doi.org/10.2305/IUCN.UK.2008.RLTS. T22578A9378011.en

Borisenko A.V. \& Kruskop S.V. 2003. Bats of Vietnam and Adjacent Territories: An Identification Manual. Geos, Moscow. 
TU V.T. et al., Phylogeography of Tylonycteris in Southeast Asia

Bystriakova N., Kapos V., Lysenko I. \& Stapleton C.M.A. 2003a. Distribution and conservation status of forest bamboo biodiversity in the Asia-Pacific Region. Biodiversity and Conservation 12 (9): 18331841. http://dx.doi.org/10.1023/A:1024139813651

Bystriakova N., Kapos V., Stapleton C. \& Lysenko I. 2003b. Bamboo Biodiversity: Information for Planning Conservation and Management in the Asia-Pacific Region. UNEP-WCMC, INBAR, Cambridge, U.K.

Castella V., Ruedi M. \& Excoffier L. 2001. Contrasted patterns of mitochondrial and nuclear structure among nursery colonies of the bat Myotis myotis. Journal of Evolutionary Biology 14 (5): 708-720. http://dx.doi.org/10.1046/j.1420-9101.2001.00331.x

Corbet G.B. \& Hill J.E. 1992. The Mammals of the Indomalayan Region: A Systematic Review. Natural History Museum, London and Oxford University Press, Oxford.

Drummond A.J., Suchard M.A., Xie D. \& Rambaut A. 2012. Bayesian phylogenetics with BEAUti and the BEAST 1.7. Molecular Biology and Evolution 29: 1969-1973. http://dx.doi.org/10.1093/molbev/ $\underline{\operatorname{mss} 075}$

Feng Q., Li S. \& Wang Y. 2008. A new species of bamboo bat (Chiroptera: Vespertilionidae: Tylonycteris) from Southwestern China. Zoological Science 25 (2): 225-234. http://dx.doi.org/10.2108/zsj.25.225

Flanders J., Wei L., Rossiter S.J. \& Zhang S. 2011. Identifying the effects of the Pleistocene on the greater horseshoe bat, Rhinolophus ferrumequinum, in East Asia using ecological niche modelling and phylogenetic analyses. Journal of Biogeography 38 (3): 439-452. http://dx.doi.org/10.1111/j.13652699.2010.02411.x

Francis C.M. 2008. A Field Guide to the Mammals of South-East Asia. New Holland Publishers, London.

Francis C.M., Borisenko A.V., Ivanova N.V., Eger J.L., Lim B.K., Guillén-Servent A., Kruskop S.V., Mackie I. \& Hebert P.D.N. 2010. The role of DNA barcodes in understanding and conservation of mammal diversity in Southeast Asia. PLoS ONE 5 (9): e12575. http://dx.doi.org/10.1371/journal. pone. 0012575

Hammer Ø., Harper D.A.T. \& Ryan P.D. 2001. PAST: Paleontological statistics software package for education and data analysis. Palaeontologia Electronica 4 (1): e4. Available from http://palaeoelectronica.org/2001_1/past/issue1_01.htm [accessed 12 Dec. 2016].

Hassanin A. \& Ropiquet A. 2007. Resolving a zoological mystery: the kouprey is a real species. Proceedings of the Royal Society B 274 (1627): 2849-2855. http://dx.doi.org/10.1098/rspb.2007.0830

Hassanin A., Delsuc F., Ropiquet A., Hammer C., Jansen van Vuuren B., Matthee C., Ruiz-Garcia M., Catzeflis F., Areskoug V., Nguyen T.T. \& Couloux A. 2012. Pattern and timing of diversification of Cetartiodactyla (Mammalia, Laurasiatheria), as revealed by a comprehensive analysis of mitochondrial genomes. Comptes Rendus Biologies 335 (1): 32-50. http://dx.doi.org/10.1016/j.crvi.2011.11.002

Hassanin A., An J., Ropiquet A., Nguyen T.T. \& Couloux A. 2013. Combining multiple autosomal introns for studying shallow phylogeny and taxonomy of Laurasiatherian mammals: Application to the tribe Bovini (Cetartiodactyla, Bovidae). Molecular Phylogenetics and Evolution 66 (3): 766-775. http:// dx.doi.org/10.1016/j.ympev.2012.11.003

Hassanin A., Khouider S., Gembu G.-C., Goodman S.M., Kadjo B., Nesi N., Pourrut X., Nakouné E. \& Bonillo C. 2015. The comparative phylogeography of fruit bats of the tribe Scotonycterini (Chiroptera, Pteropodidae) reveals cryptic species diversity related to African Pleistocene forest refugia. Comptes Rendus Biologies 338 (3): 197-211. http://dx.doi.org/10.1016/j.crvi.2014.12.003

Hendrichsen D.K., Bates P.J.J., Hayes B.D. \& Walston J.L. 2001. Recent records of bats (Mammalia: Chiroptera) from Vietnam with six species new to the country. Myotis 39: 35-122. 
Hua P., Zhang L., Zhu G., Jones G., Zhang S. \& Rossiter S.J. 2011. Hierarchical polygyny in multiparous lesser flat-headed bats. Molecular Ecology 20 (17): 3669-3680. http://dx.doi.org/10.1111/j.1365294X.2011.05192.x

Hua P., Zhang L., Guo T., Flanders J. \& Zhang S. 2013. Dispersal, mating events and fine-scale genetic structure in the lesser flat-headed bats. PLOS ONE 8 (1): e54428. http://dx.doi.org/10.1371/journal. pone. 0054428

Huang C., Yu W., Xu Z., Qiu Y., Chen M., Qiu B., Motokawa M., Harada M., Li Y. \& Wu Y. 2014. A cryptic species of the Tylonycteris pachypus complex (Chiroptera: Vespertilionidae) and its population genetic structure in southern China and nearby regions. International Journal of Biological Sciences 10 (2): 200-211. http://dx.doi.org/10.7150/ijbs.7301

Hulva P., Fornŭsková A., Chudárková A., Evin A., Allegrini B., Benda P. \& Bryja J. 2010. Mechanisms of radiation in a bat group from the genus Pipistrellus inferred by phylogeography, demography and population genetics. Molecular Ecology 19 (24): 5417-5431. http://dx.doi.org/10.1111/j.1365$\underline{294 X .2010 .04899 . x}$

Inger R.F. \& Voris H.K. 2001. The biogeographical relations of the frogs and snakes of Sundaland. Journal of Biogeography 28 (7): 863-891. http://dx.doi.org/10.1046/j.1365-2699.2001.00580.x

Jones K.E., Purvis A., MacLarnon A., Bininda-Emonds O.R.P. \& Simmons N.B. 2002. A phylogenetic supertree of the bats (Mammalia: Chiroptera). Biological Reviews 77 (2): 223-259. http://dx.doi. org/10.1017/S1464793101005899

Jungers W.L., Falsetti A.B. \& Wall C.E. 1995. Shape, relative size, and size-adjustments in morphometrics. American Journal of Physical Anthropology 38 (S21): 137-161. http://dx.doi. org/10.1002/ajpa.1330380608

Khan F.A.A., Solari S., Swier V.J., Larsen P.A., Abdullah M.T. \& Baker R.J. 2010. Systematics of Malaysian woolly bats (Vespertilionidae: Kerivoula) inferred from mitochondrial, nuclear, karyotypic, and morphological data. Journal of Mammalogy 91 (5): 1058-1072. http://dx.doi.org/10.1644/09MAMM-A-361.1

Kingston T. 2010. Research priorities for bat conservation in Southeast Asia: a consensus approach. Biodiversity and Conservation 19 (2): 471-484. http://dx.doi.org/10.1007/s10531-008-9458-5

Kruskop S.V. 2013. Bats of Vietnam: Checklist and an Identification Manual. KMK Sci Press, Moscow.

Kunz T.H. 1982. Roosting ecology of bats. In: Kunz T.H. (ed.) Ecology of Bats: 1-55. Springer, New York.

Lande R. \& Barrowclough G. 1987. Effective population size, genetic variation, and their use in population management. In: Soulé M.E. (ed.) Viable Populations for Conservation: 87-124. Cambridge University Press, London.

Lin A.Q., Csorba G., Li L.F., Jiang T.L., Lu G.J., Thong V.D., Soisook P., Sun K.P. \& Feng J. 2014. Phylogeography of Hipposideros armiger (Chiroptera: Hipposideridae) in the Oriental Region: the contribution of multiple Pleistocene glacial refugia and intrinsic factors to contemporary population genetic structure. Journal of Biogeography 41 (2): 317-327. http://dx.doi.org/10.1111/jbi.12163

Lindenfors P., Gittleman J.L. \& Jones K.E. 2007. Sexual size dimorphism in mammals. In: Fairbairn D.J., Blanckenhorn W.U. \& Székely T. (eds) Sex, Size and Gender Roles: Evolutionary Studies of Sexual Size Dimorphism: 16-26. Oxford University Press, Oxford.

Mao X.G., Zhu G.J., Zhang S. \& Rossiter S.J. 2010. Pleistocene climatic cycling drives intra-specific diversification in the intermediate horseshoe bat (Rhinolophus affinis) in Southern China. Molecular Ecology 19 (13): 2754-2769. http://dx.doi.org/10.1111/j.1365-294X.2010.04704.x 
TU V.T. et al., Phylogeography of Tylonycteris in Southeast Asia

Mao X.G., He G.M., Zhang J.P., Rossiter S.J. \& Zhang S.Y. 2013. Lineage divergence and historical gene flow in the Chinese horseshoe bat (Rhinolophus sinicus). PLoS ONE 8 (2): e56786. http://dx.doi. org/10.1371/journal.pone.0056786

Medway L. 1972. Reproductive cycles of the flat-headed bats Tylonycteris pachypus and T. robustula (Chiroptera: Vespertilioninae) in a humid equatorial environment. Zoological Journal of the Linnean Society 51 (1): 33-61. http://dx.doi.org/10.1111/j.1096-3642.1972.tb00772.x

Medway L. 1973. The taxonomic status of Tylonycteris malayana Chasen 1940 (Chiroptera). Journal of Natural History 7 (2): 125-131. http://dx.doi.org/10.1080/00222937300770111

Medway L. \& Marshall A.G. 1970. Roost-site selection among flat-headed bats (Tylonycteris spp.). Journal of Zoology 161 (2): 237-245. http://dx.doi.org/10.1111/j.1469-7998.1970.tb02038.x

Medway L. \& Marshall A.G. 1972. Roosting associations of flat-headed bats, Tylonycteris species (Chiroptera: Vespertilionidae) in Malaysia. Journal of Zoology 168 (4): 463-482. http://dx.doi. org/10.1111/j.1469-7998.1972.tb01362.x

Meijaard E. \& Groves C.P. 2006. The geography of mammals and rivers in mainland Southeast Asia. In: Lehman S.M. \& Fleagle J.G. (eds) Primate Biogeography: 305-329. Springer, New York.

Morley R.J. 2000. Origin and Evolution of Tropical Rain Forests. John Wiley \& Sons, Chichester, U.K.

Nesi N., Nakouné E., Cruaud C. \& Hassanin A. 2011. DNA barcoding of African fruit bats (Mammalia, Pteropodidae). The mitochondrial genome does not provide a reliable discrimination between Epomophorus gambianus and Micropteropus pusillus. Comptes Rendus Biologies 334 (7): 544-554. http://dx.doi.org/10.1016/j.crvi.2011.05.003

Nesi N., Kadjo B., Pourrut X., Leroy E., Pongombo Shongo C., Cruaud C. \& Hassanin A. 2013. Molecular systematics and phylogeography of the tribe Myonycterini (Mammalia, Pteropodidae) inferred from mitochondrial and nuclear markers. Molecular Phylogenetics and Evolution 66 (1): 126-137. http:// dx.doi.org/10.1016/j.ympev.2012.09.028

Osgood W.H. 1932. Mammals of the Kelley-Roosevelts and Delacour Asiatic expedition. Field Museum of Natural History, Zoological Series 18: 193-339. Available from http://dx.doi.org/10.5962/bhl.

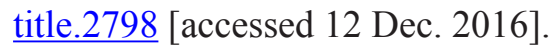

Pereira M.J.R., Salgueiro P., Rodrigues L., Coelho M.M. \& Palmeirim J.M. 2009. Population structure of a cave-dwelling bat, Miniopterus schreibersii: Does it reflect history and social organization? Journal of Heredity 100 (5): 533-544. http://dx.doi.org/10.1093/jhered/esp032

Posada D. 2008. jModelTest: Phylogenetic model averaging. Molecular Biology and Evolution 25 (7): 1253-1256. http://dx.doi.org/10.1093/molbev/msn083

Rambaut A. 2002. Sequence Alignment Editor, v. 2.0 alpha 11. Available from http://evolve.zoo.ox.ac. uk/ [accessed 12 Dec. 2016]

Rambaut A. 2009. FigTree, v. 1.4.0, 2006-2012. Available from http://tree.bio.ed.ac.uk/software/figtree/ [accessed 12 Dec. 2016].

Rivers N.M., Butlin R.K. \& Altringham J.D. 2005. Genetic population structure of Natterer's bats explained by mating at swarming sites and philopatry. Molecular Ecology 14 (14): 4299-4312. http:// dx.doi.org/10.1111/j.1365-294X.2005.02748.x

Roehrs Z.P., Lack J.B. \& Van Den Bussche R.A. 2010. Tribal phylogenetic relationships within Vespertilioninae (Chiroptera: Vespertilionidae) based on mitochondrial and nuclear sequence data. Journal of Mammalogy 91 (5): 1073-1092. http://dx.doi.org/10.1644/09-MAMM-A-325.1 
Ronquist F., Teslenko M., van der Mark P., Ayres D.L., Darling A., Hohna S., Larget B., Liu L., Suchard M.A. \& Huelsenbeck J.P. 2012. MrBayes 3.2: Efficient Bayesian phylogenetic inference and model choice across a large model space. Systematic Biology 61 (3): 539-542. http://dx.doi.org/10.1093/ sysbio/sys029

Ropiquet A., Li B. \& Hassanin A. 2009. SuperTRI: A new approach based on branch support analyses of multiple independent data sets for assessing reliability of phylogenetic inferences. Comptes Rendus Biologies 332 (9): 832-847. http://dx.doi.org/10.1016/j.crvi.2009.05.001

Ruedi M. \& Castella V. 2003. Genetic consequences of the ice ages on nurseries of the bat Myotis myotis: a mitochondrial and nuclear survey. Molecular Ecology 12 (6): 1527-1540. http://dx.doi.org/10.1046/ j.1365-294X.2003.01828.X

Shaffer M.L. 1981. Minimum population sizes for species conservation. BioScience 31 (2): 131-134. http://dx.doi.org/10.2307/1308256

Simmons N.B. 2005. Order Chiroptera. In: Wilson D.E. \& Reeder D.M. (eds) Mammal Species of the World: A Taxonomic and Geographic Reference: 312-529. Johns Hopkins University Press, London.

Sodhi N.S., Posa M.R.C., Lee T.M., Bickford D., Koh L.P. \& Brook B.W. 2010. The state and conservation of Southeast Asian biodiversity. Biodiversity and Conservation 19 (2): 317-328. http:// dx.doi.org/10.1007/s10531-009-9607-5

Swofford D.L. 2003. PAUP*: Phylogenetic Analysis Using Parsimony (*and other methods), v. 4. Sinauer Associates, Sunderland, Massachusetts.

Thewissen J.G.M. \& Etnier S.A. 1995. Adhesive devices on the thumb of vespertilionoid bats (Chiroptera). Journal of Mammalogy 76 (3): 925-936. http://dx.doi.org/10.2307/1382762

Thomas N.M., Duckworth J.W., Douangboubpha B., Williams M. \& Francis C.M. 2013. A checklist of bats (Mammalia: Chiroptera) from Lao PDR. Acta Chiropterologica 15 (1): 193-260. http://dx.doi. org/10.3161/150811013X667993

Tordoff A.W., Bezuijen M.R., Duckworth J.W., Fellowes J.R., Koenig K., Pollard E.H.B. \& Royo A.G. 2012. Ecosystem Profile: Indo-Burma Biodiversity Hotspot Indochina Region. Final Version October 2012. Critical Ecosystem Partnership Fund, Conservation International, USA.

Voris H.K. 2000. Maps of Pleistocene sea levels in Southeast Asia: shorelines, river systems and time durations. Journal of Biogeography 27 (5): 1153-1167. http://dx.doi.org/10.1046/j.1365$\underline{2699.2000 .00489 . x}$

Woodruff D.S. 2010. Biogeography and conservation in Southeast Asia: how 2.7 million years of repeated environmental fluctuations affect today's patterns and the future of the remaining refugialphase biodiversity. Biodiversity and Conservation 19 (4): 919-941. http://dx.doi.org/10.1007/s10531$\underline{010-9783-3}$

Yuming Y., Kanglin W., Shengji P. \& Jiming H. 2004. Bamboo diversity and traditional uses in Yunnan, China. Mountain Research and Development 24 (2): 157-165. http://dx.doi.org/10.1659/02764741(2004)024[0157:BDATUI]2.0.CO;2

Zar J.H. 1999. Biostatistical Analysis, fourth edition. Upper Saddle River, Prentice Hall, New Jersey.

Zhang L., Liang B., Parsons S., Wei L. \& Zhang S. 2007. Morphology, echolocation and foraging behaviour in two sympatric sibling species of bat (Tylonycteris pachypus and Tylonycteris robustula) (Chiroptera: Vespertilionidae). Journal of Zoology 271 (3): 344-351. http://dx.doi.org/10.1111/j.1469$\underline{7998.2006 .00210 . x}$ 
Zhang L.B., Liang B., Zhou S.Y., Lu L.R. \& Zhang S.Y. 2004. Group structure of lesser flat-headed bat Tylonycteris pachypus and greater flat-headed bat T. robustula. Acta Zoologica Sinica 50 (3): 326-333.

Zhang L.B., Jones G., Rossiter S., Ades G., Liang B. \& Zhang S.Y. 2005. Diet of flat-headed bats, Tylonycteris pachypus and T. robustula, in Guangxi, South China. Journal of Mammalogy 86 (1): 61-66. http://dx.doi.org/10.1644/1545-1542(2005)086<0061:DOFBTP>2.0.CO;2

Manuscript received: 2 March 2016

Manuscript accepted: 1 August 2016

Published on: 9 February 2017

Guest editors: Line Le Gall, Frédéric Delsuc, Stéphane Hourdez, Guillaume Lecointre

and Jean-Yves Rasplus

Desk editor: Danny Eibye-Jacobsen

Printed versions of all papers are also deposited in the libraries of the institutes that are members of the EJT consortium: Muséum national d'Histoire naturelle, Paris, France; Botanic Garden Meise, Belgium; Royal Museum for Central Africa, Tervuren, Belgium; Natural History Museum, London, United Kingdom; Royal Belgian Institute of Natural Sciences, Brussels, Belgium; Natural History Museum of Denmark, Copenhagen, Denmark; Naturalis Biodiversity Center, Leiden, the Netherlands. 


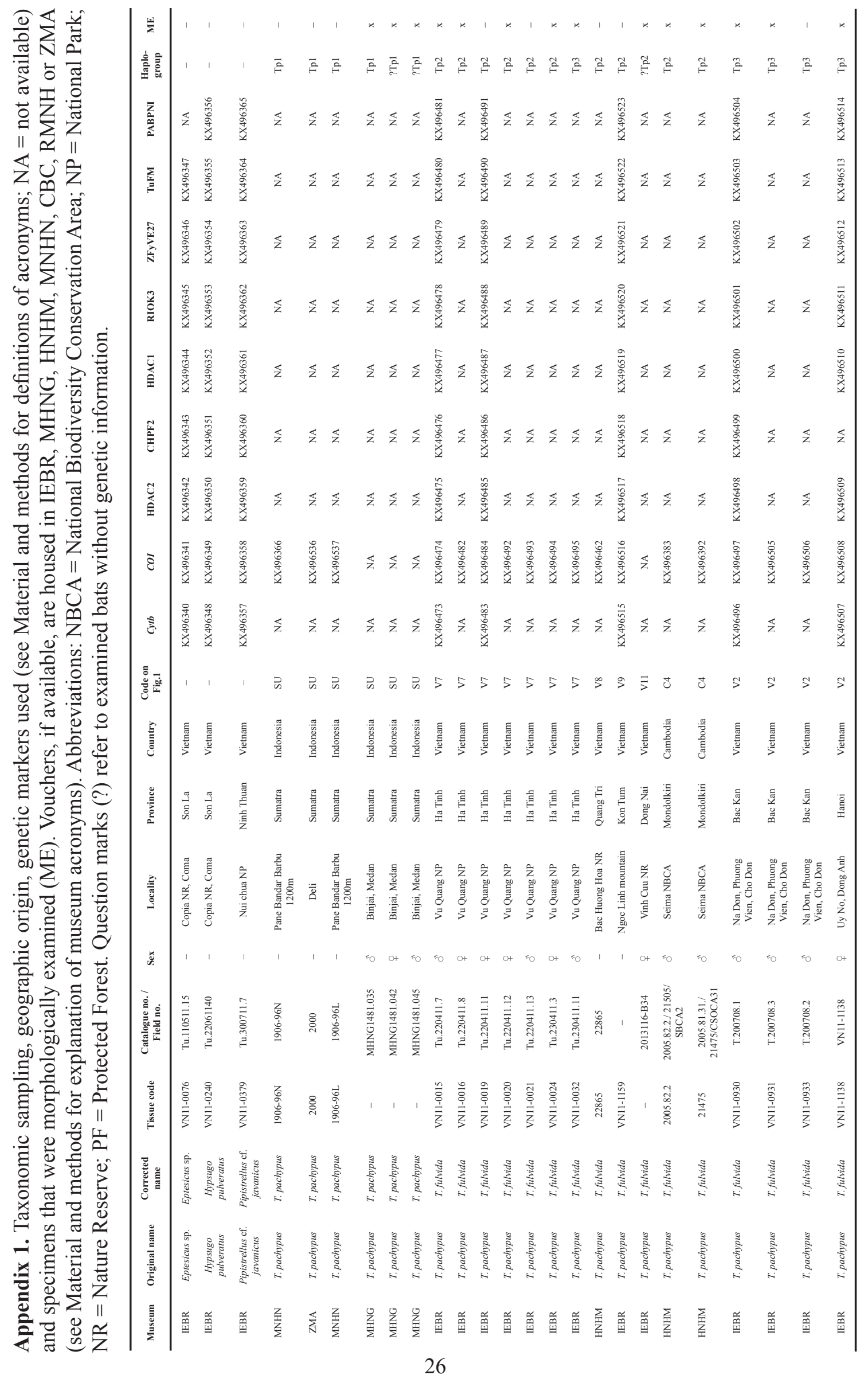




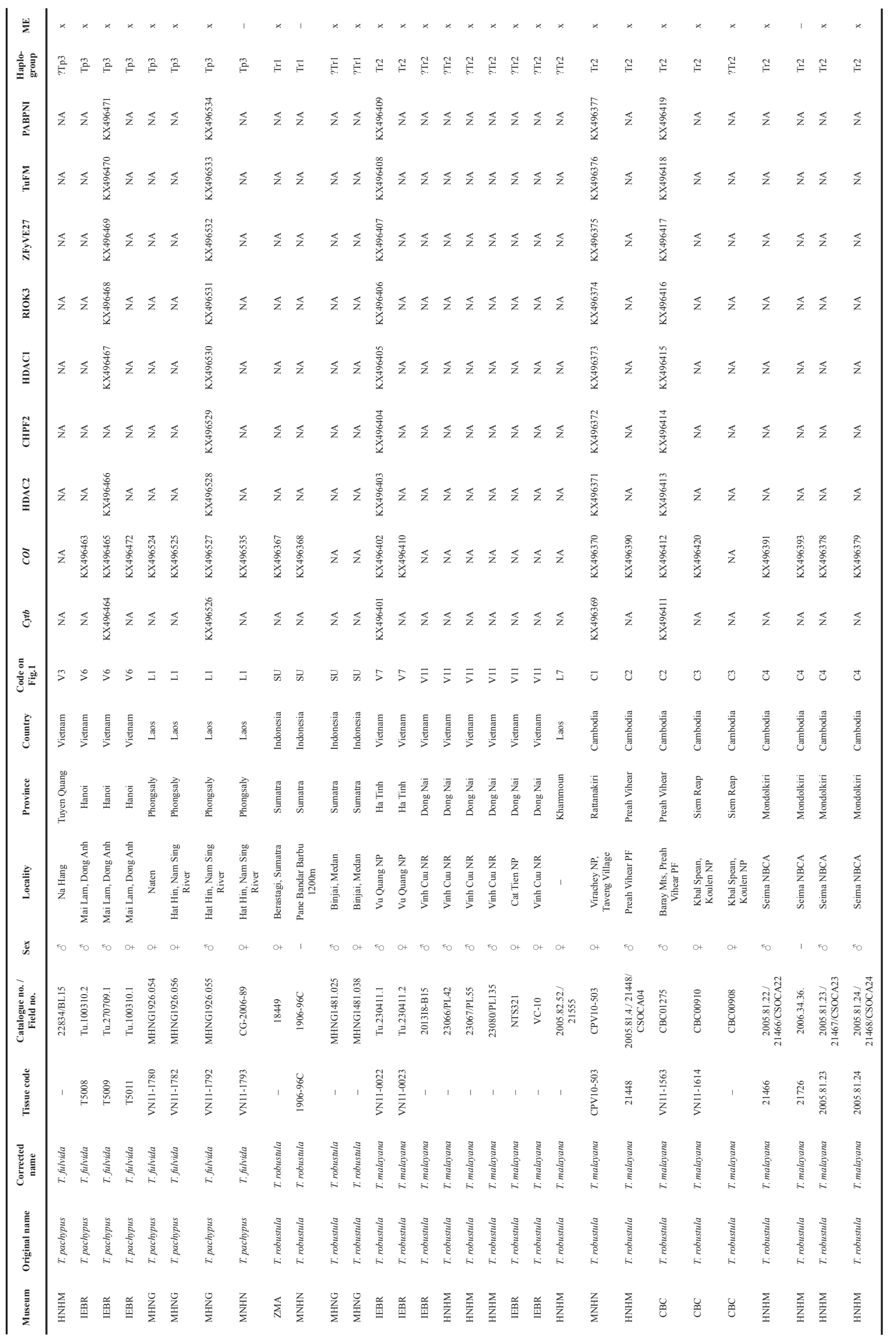




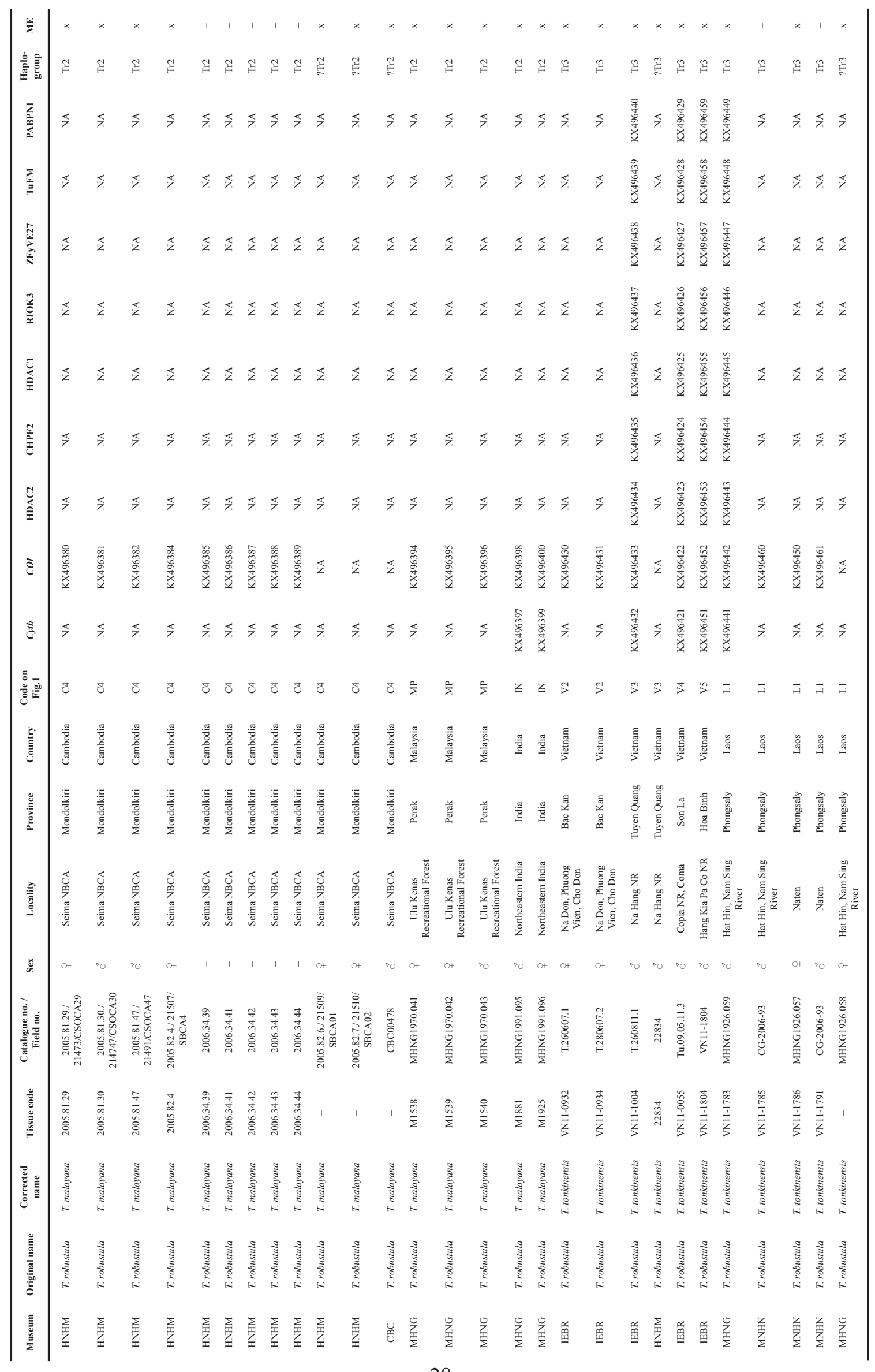




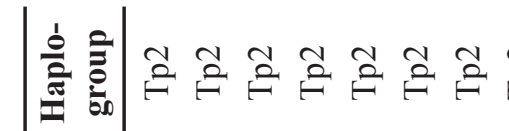

ริ 2

$\sim \varkappa$

$m \infty$

$\hat{2} \approx$

\section{$\lim ^{2}$}

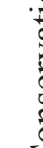

$\sum_{0}$
0
0
0

空

है

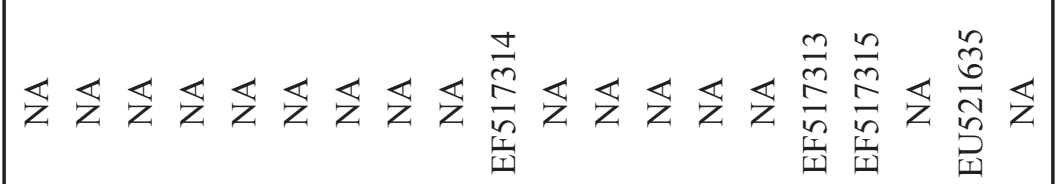

$\stackrel{0}{\circ}$

葛

$\bigcup^{\|}$

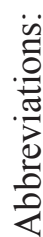

0
0
0
0
0
0
0
0
0
0
0
0
0
0
0
0
0

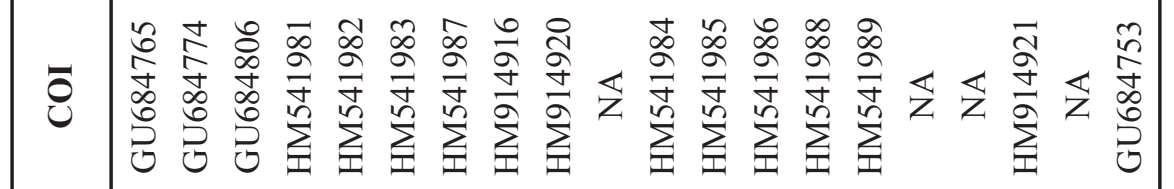

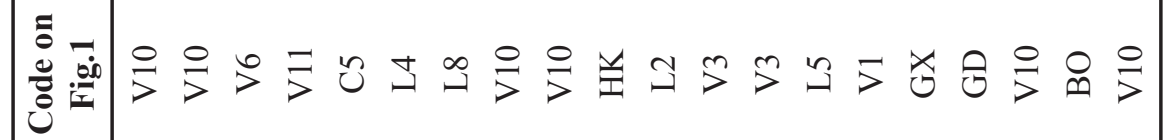

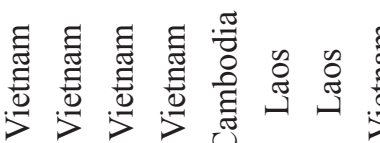

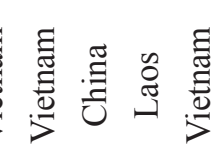

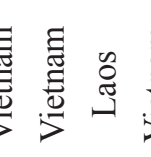

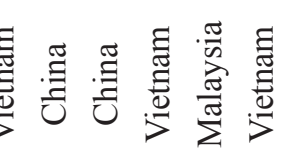

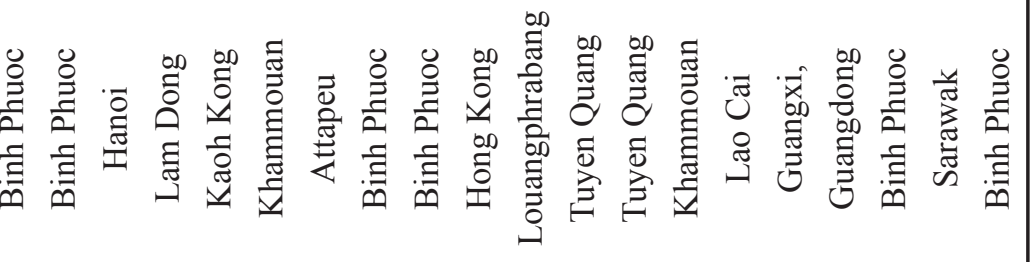

产

है

i

.

鄫

을

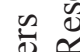

言

흔

窇

远

光艺

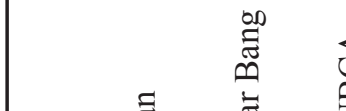

(2) 


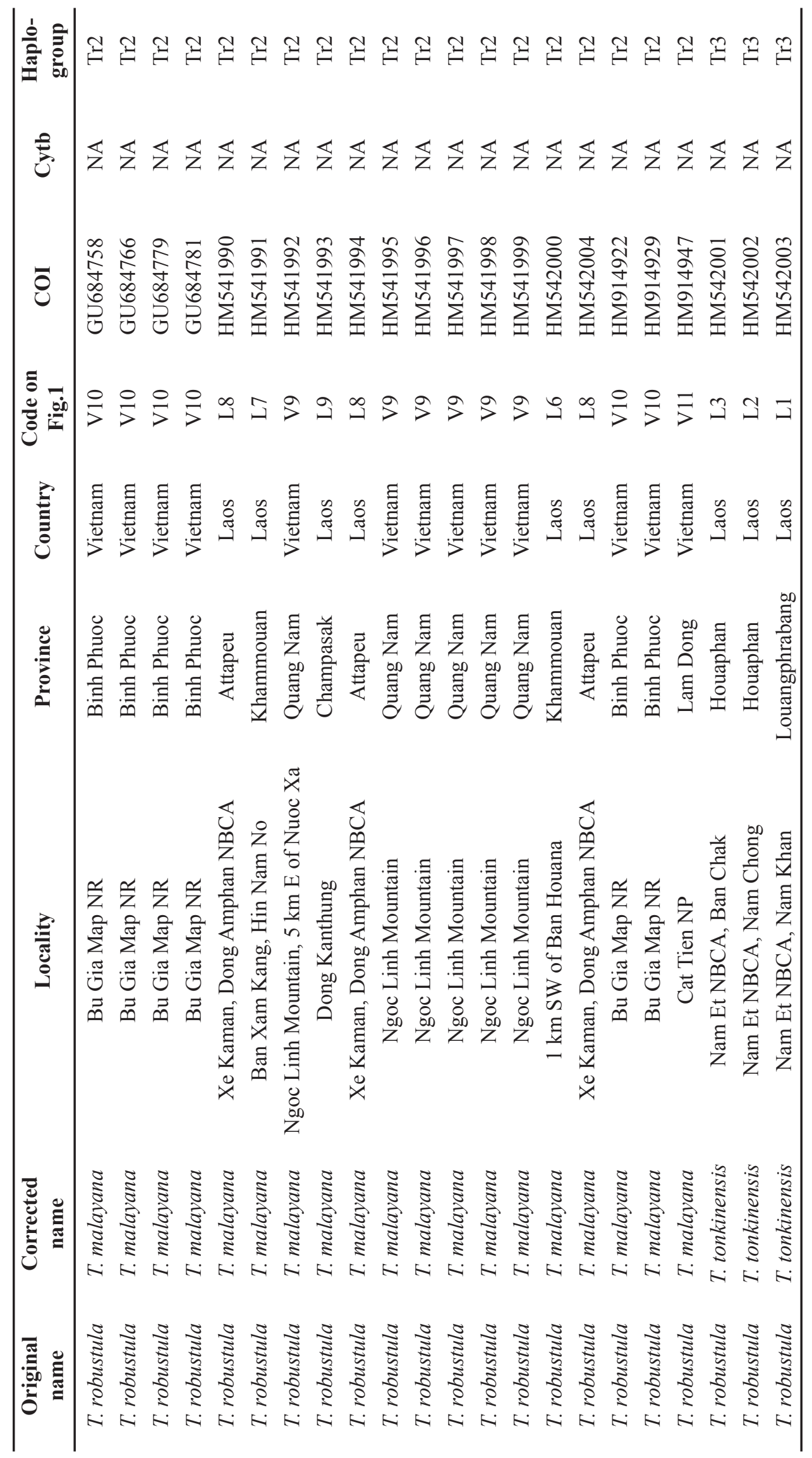


Appendix 3. Bayesian tree of Tylonycteris Peters, 1872 and associated outgroups obtained from the analysis of an alignment of COI gene $291 \mathrm{nt}$.

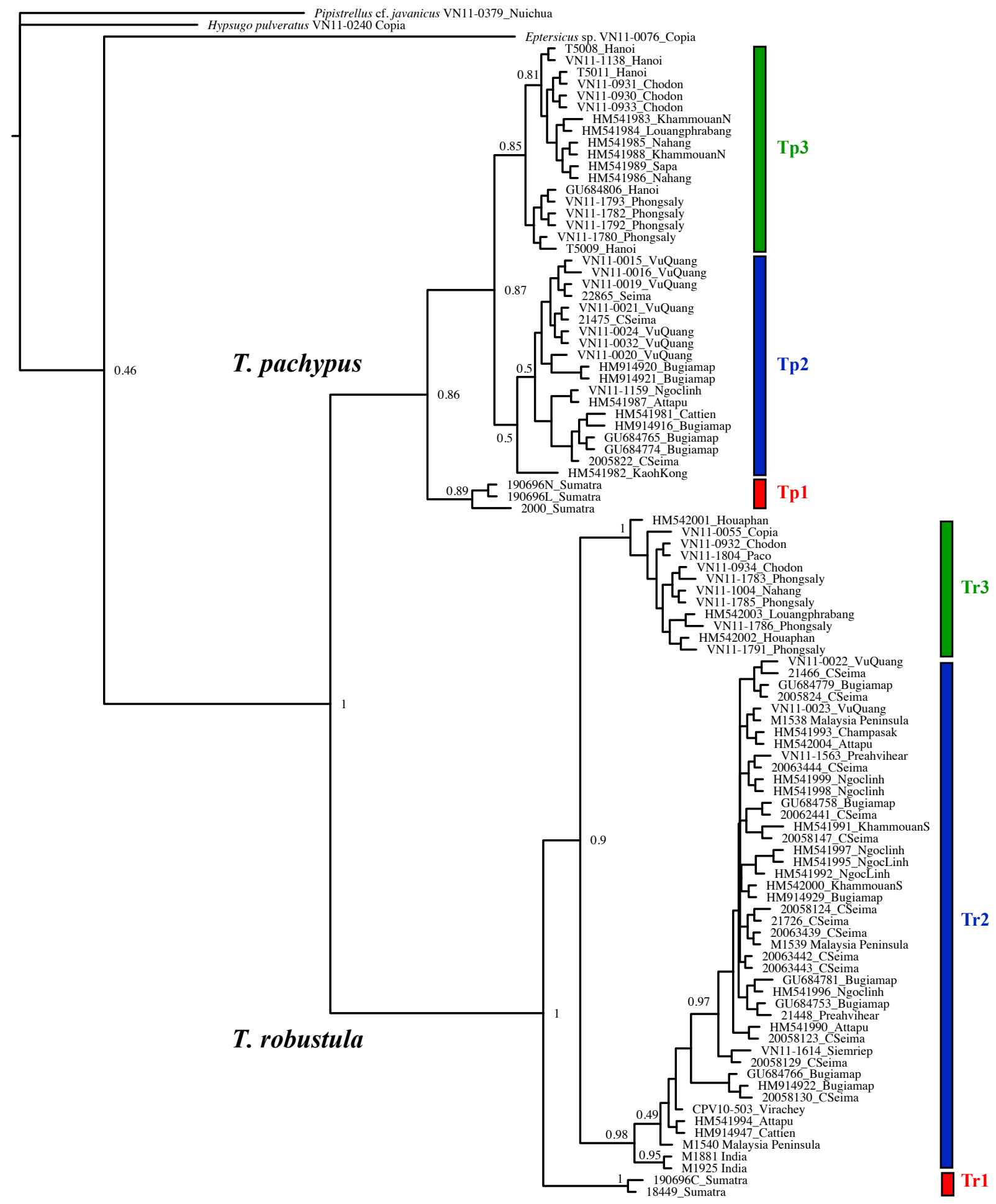




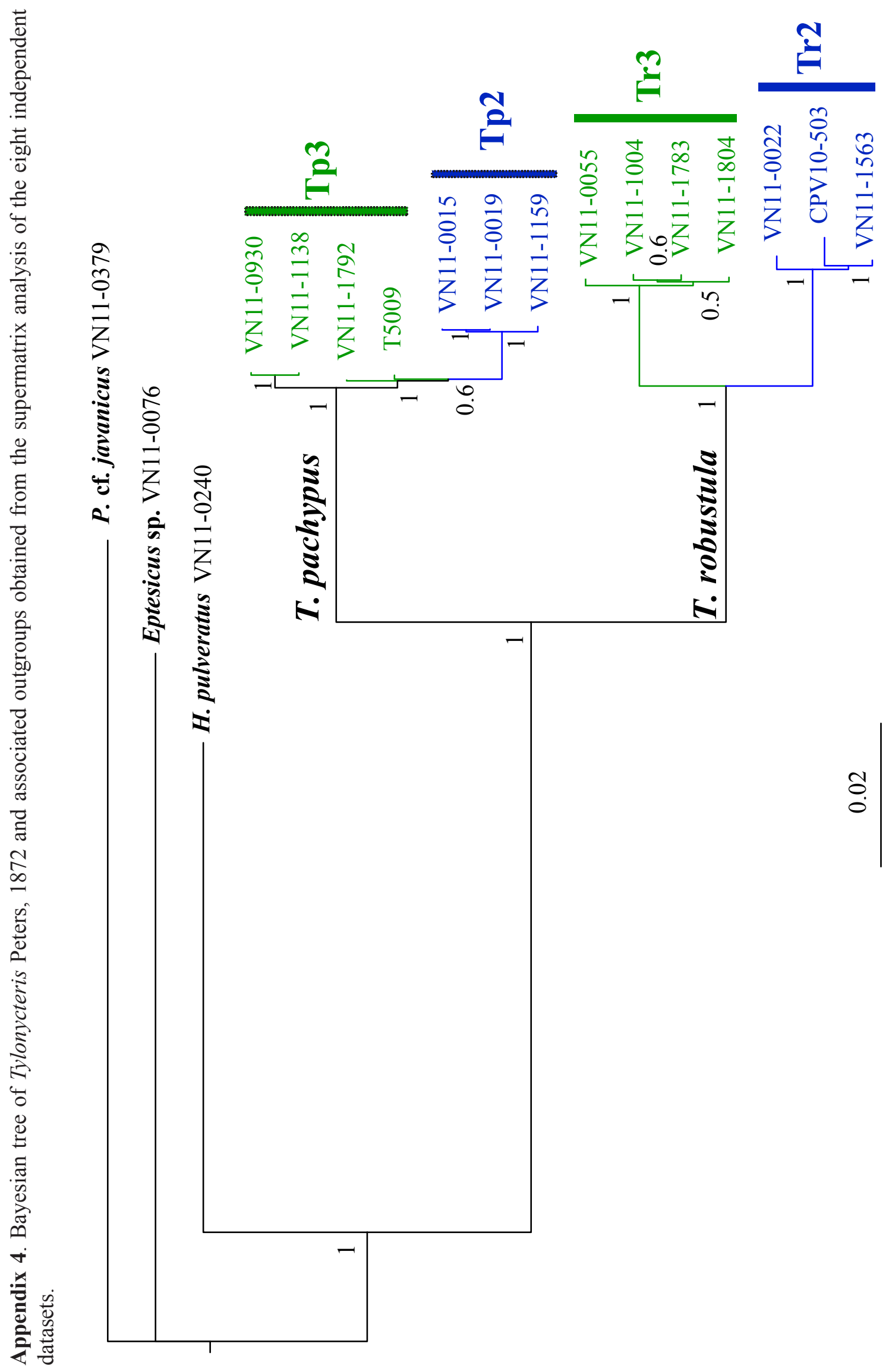




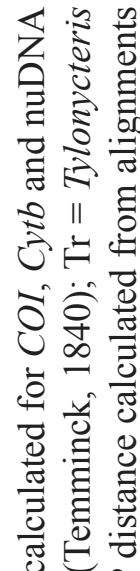

के

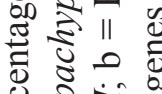

过

$\exists \div$

寻荬

घี Е

零范

䒕的完

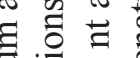

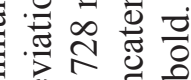

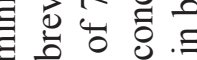

뉴

웛

我嘕节

ปิ

อㄹ.

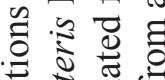

莺 吾

.

品

능 워

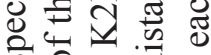

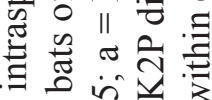

응

त 100

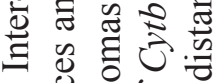

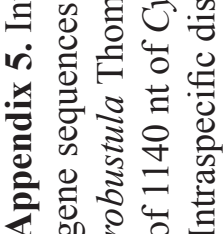

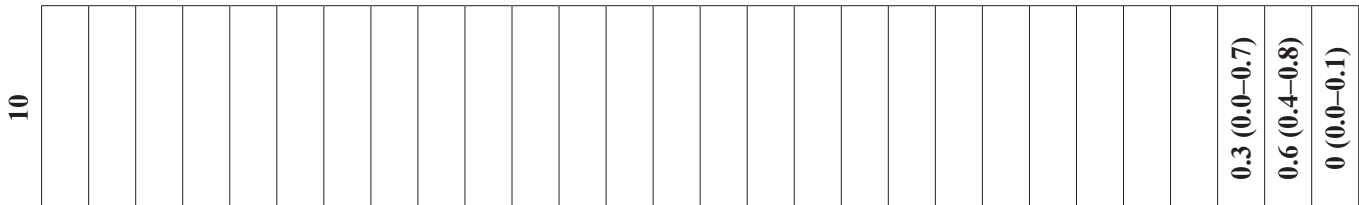

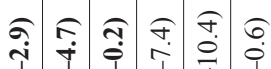

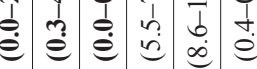

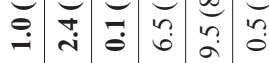

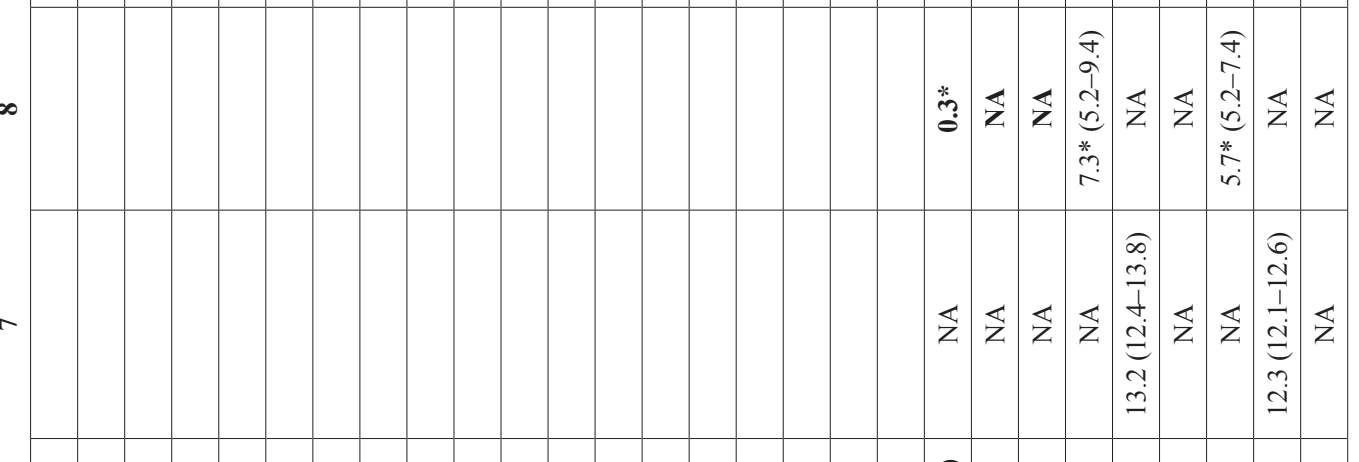

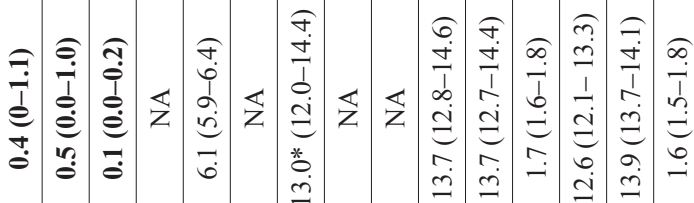

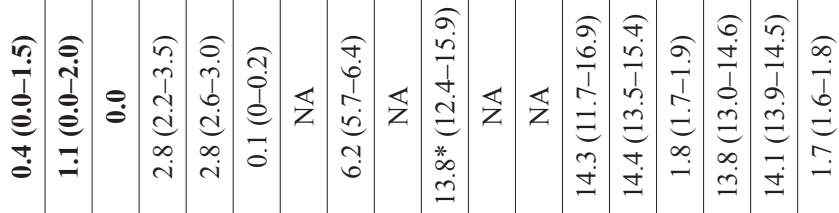

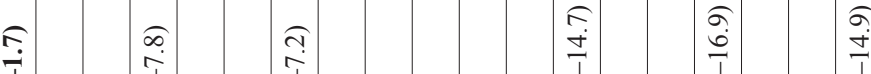

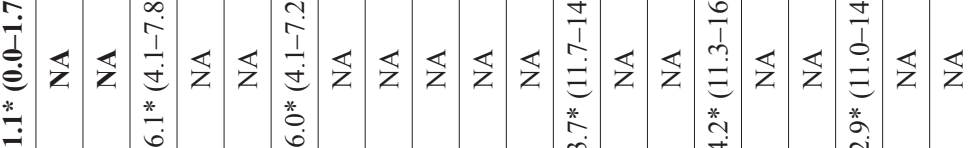

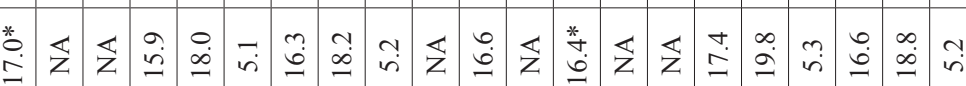

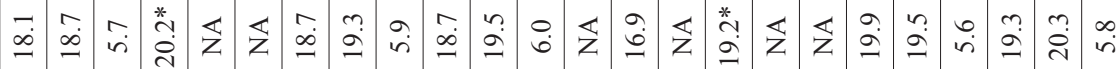

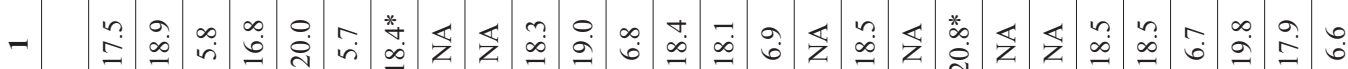

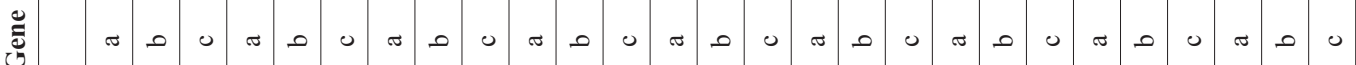

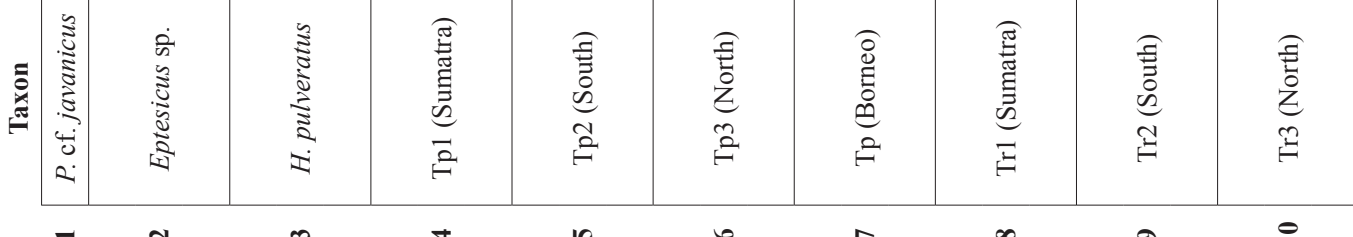




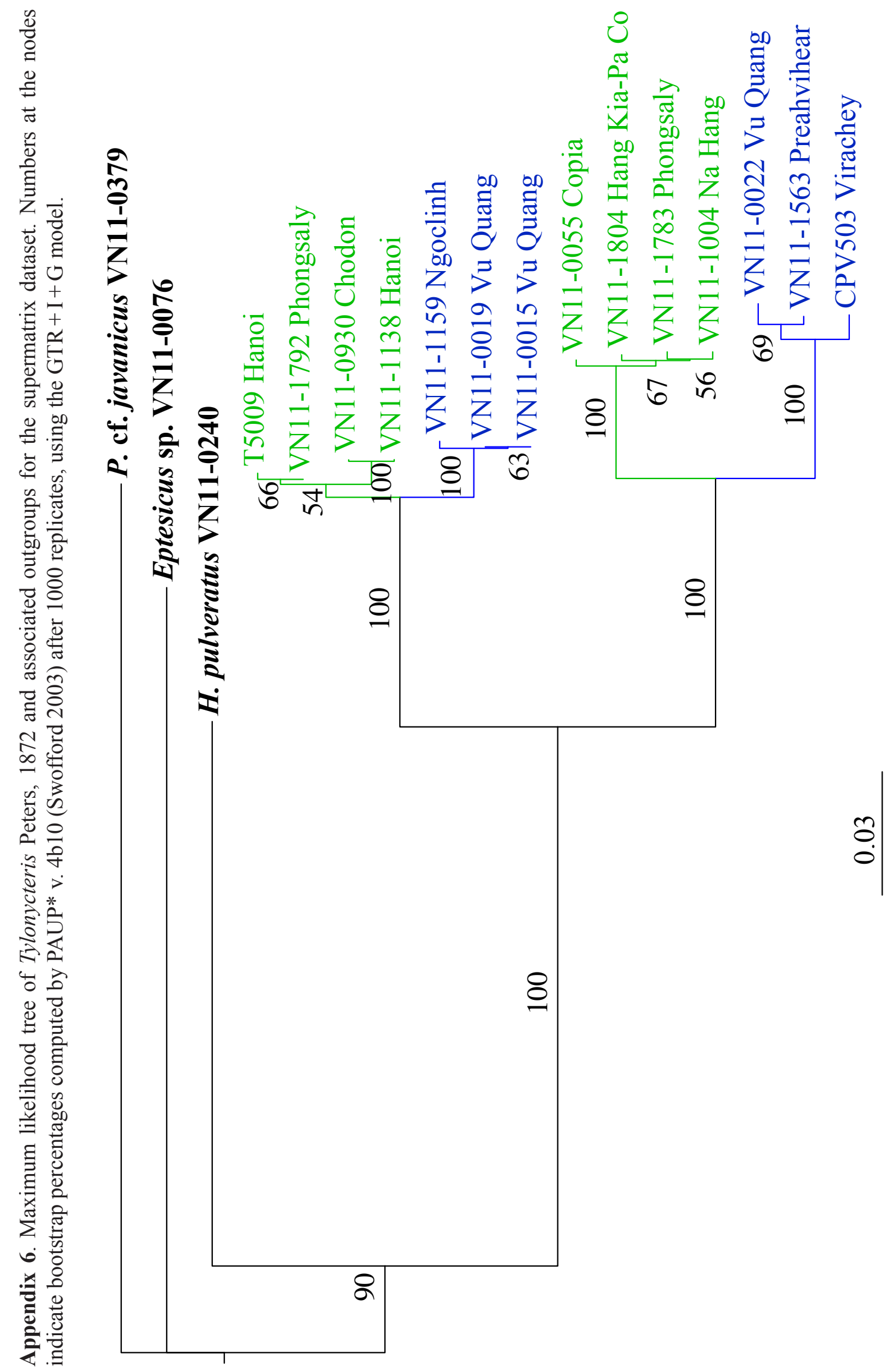


Appendix 7. 1. Supertree Bootstrap majority-rule consensus tree with Supertree Bootstrap percentages (SBP)

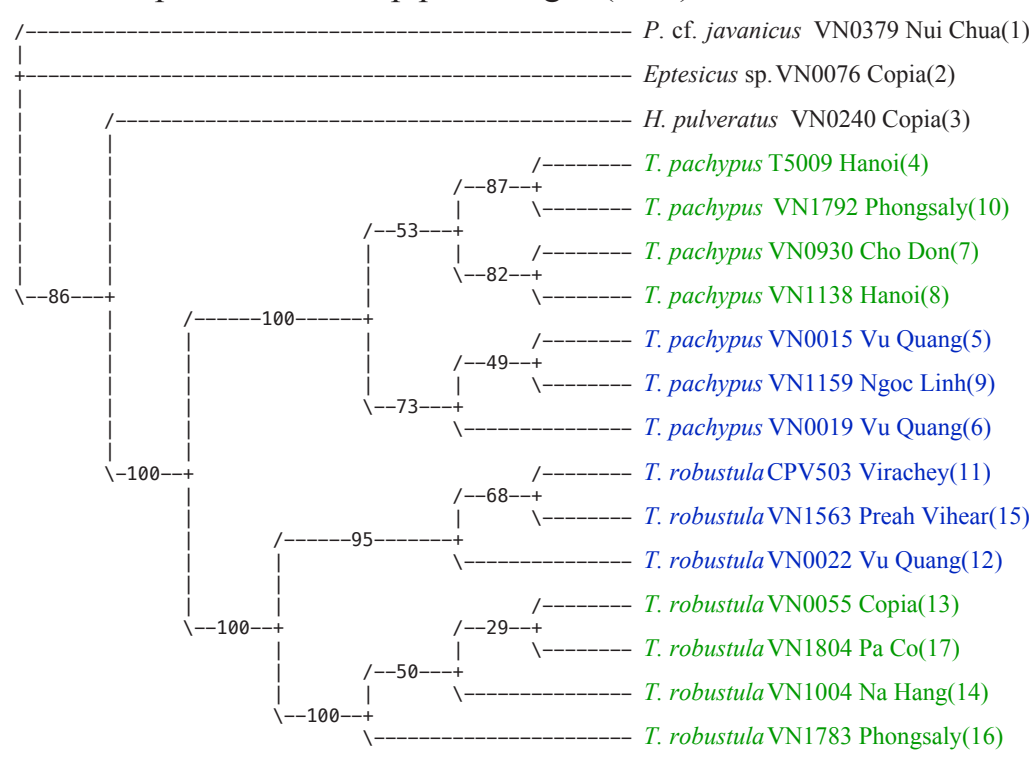

Appendix 7. 2. Mean posterior probabilities (MPP)

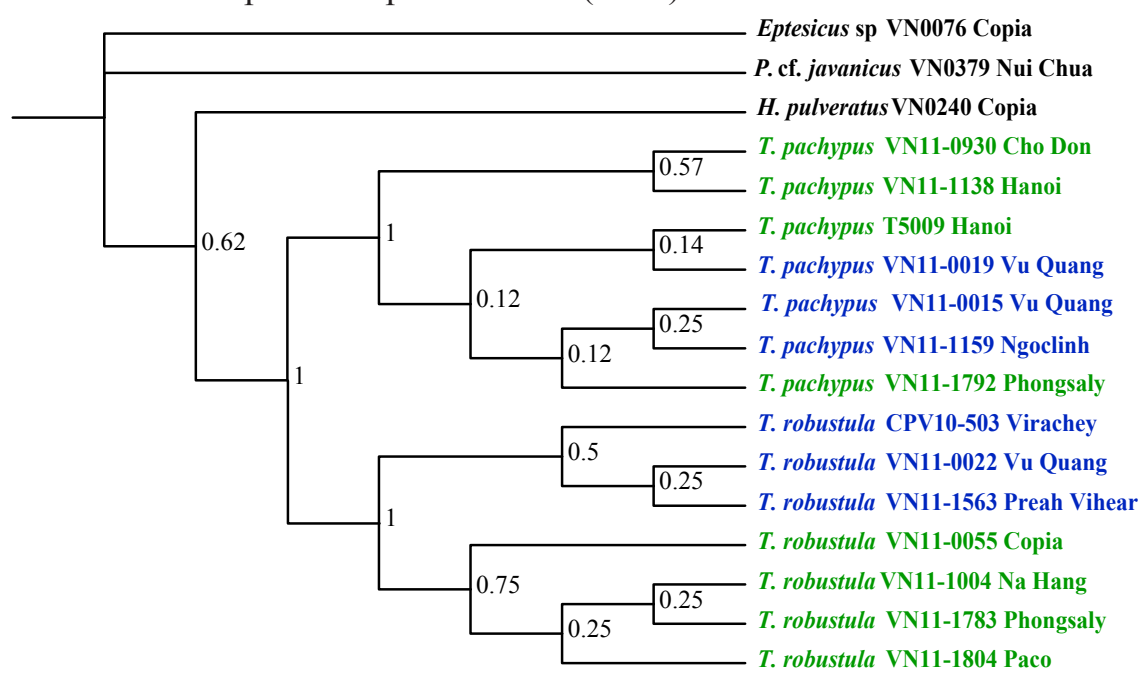

Appendix 7.3. Indices of reproducibility (Rep)

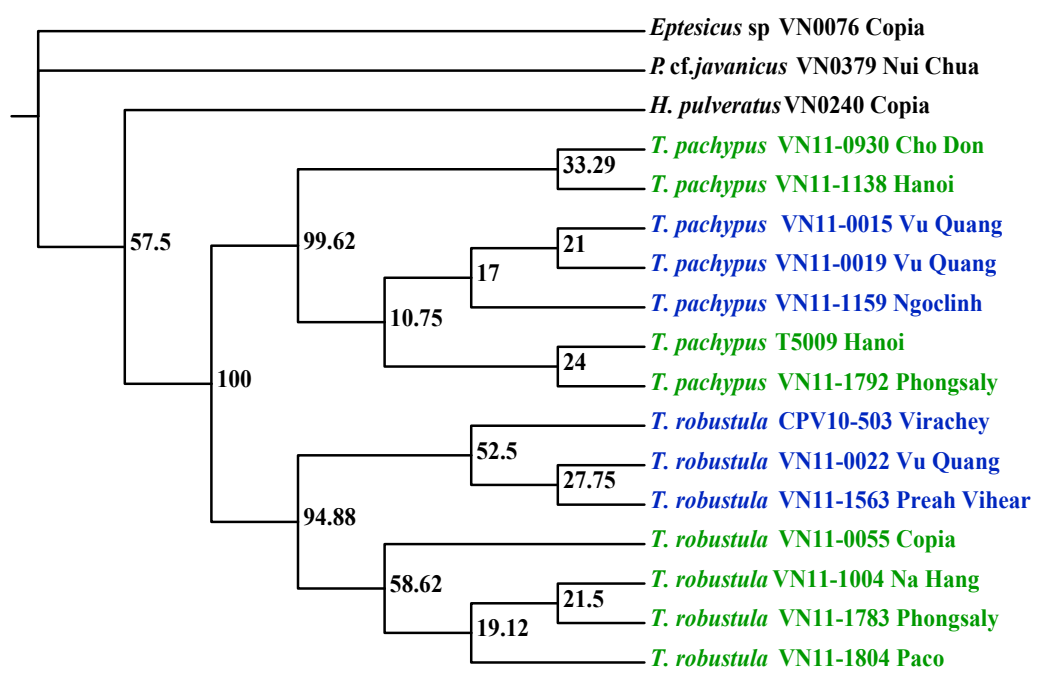


Appendix 8. Bayesian trees reconstructed from the separate analyses of the eight independent datasets (mtDNA [COI + Cytb], CHPF2, HDAC1, HDAC2, PABPN1, RIOK3, TUFM and ZFYVE27).

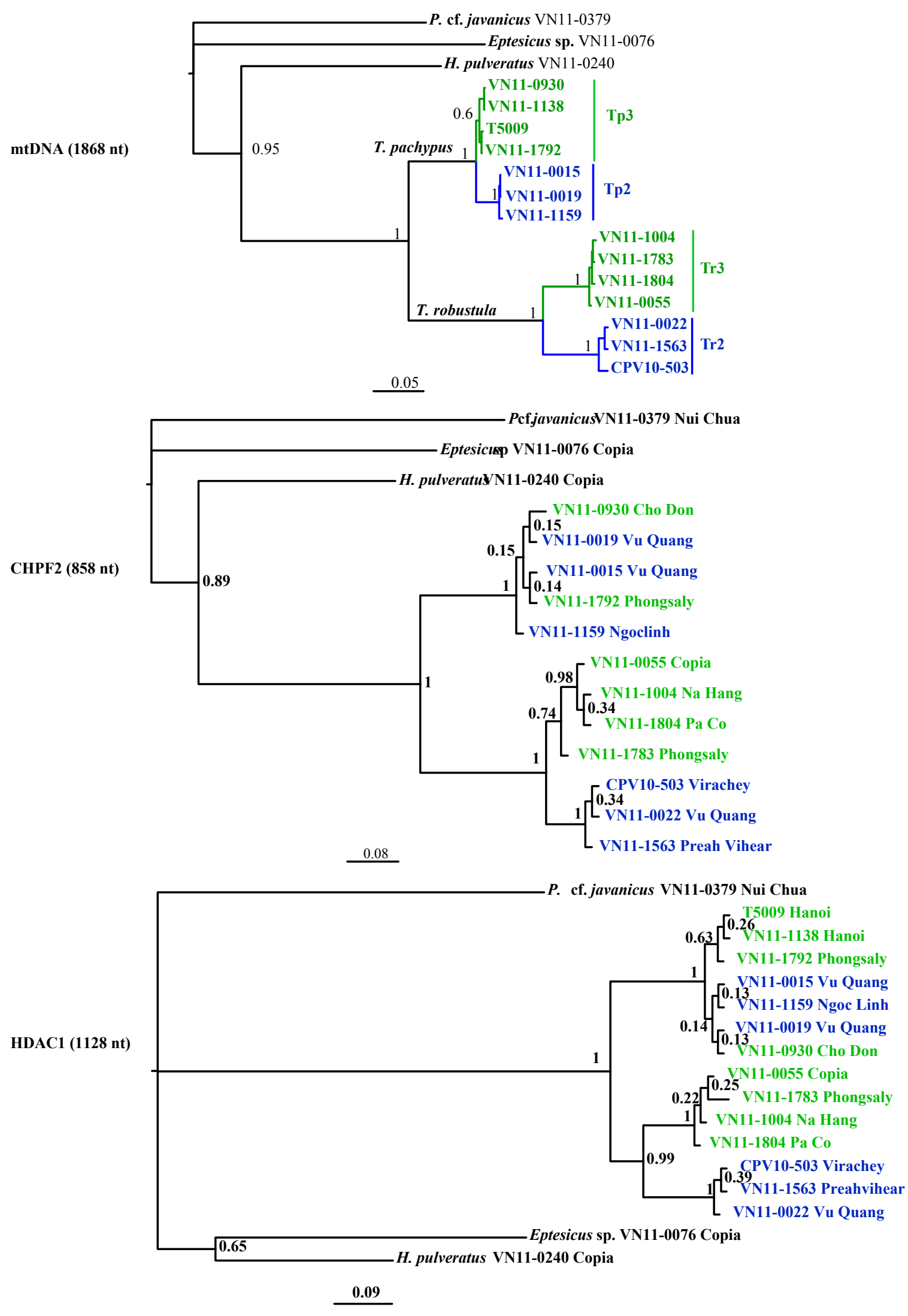


Appendix 8. Bayesian trees reconstructed from the separate analyses of the eight independent datasets (mtDNA [COI + Cytb], CHPF2, HDAC1, HDAC2, PABPN1, RIOK3, TUFM and ZFYVE27) (Contituned).

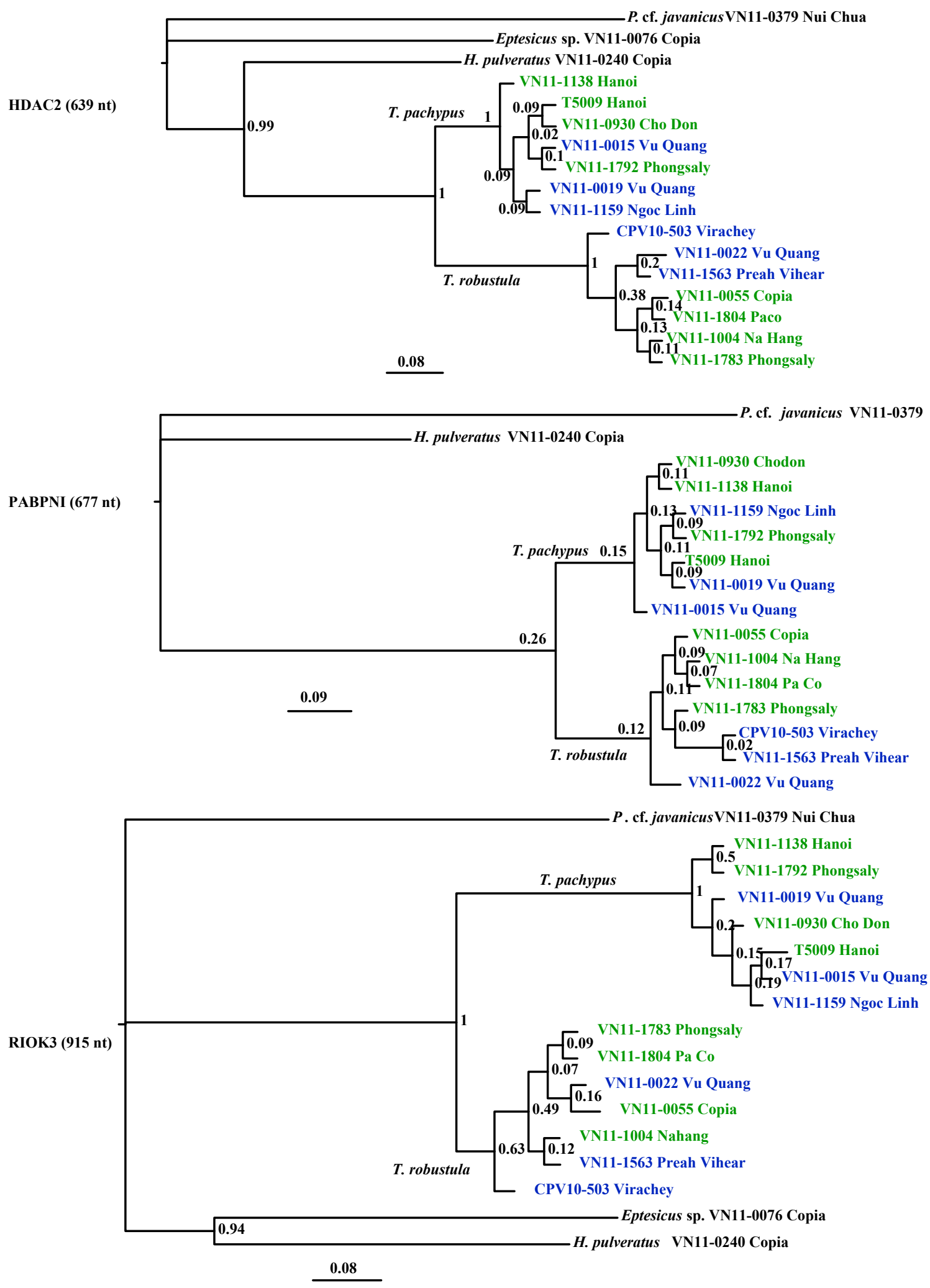


Appendix 8. Bayesian trees reconstructed from the separate analyses of the eight independent datasets (mtDNA [COI + Cytb], CHPF2, HDAC1, HDAC2, PABPN1, RIOK3, TUFM and ZFYVE27) (Continued).
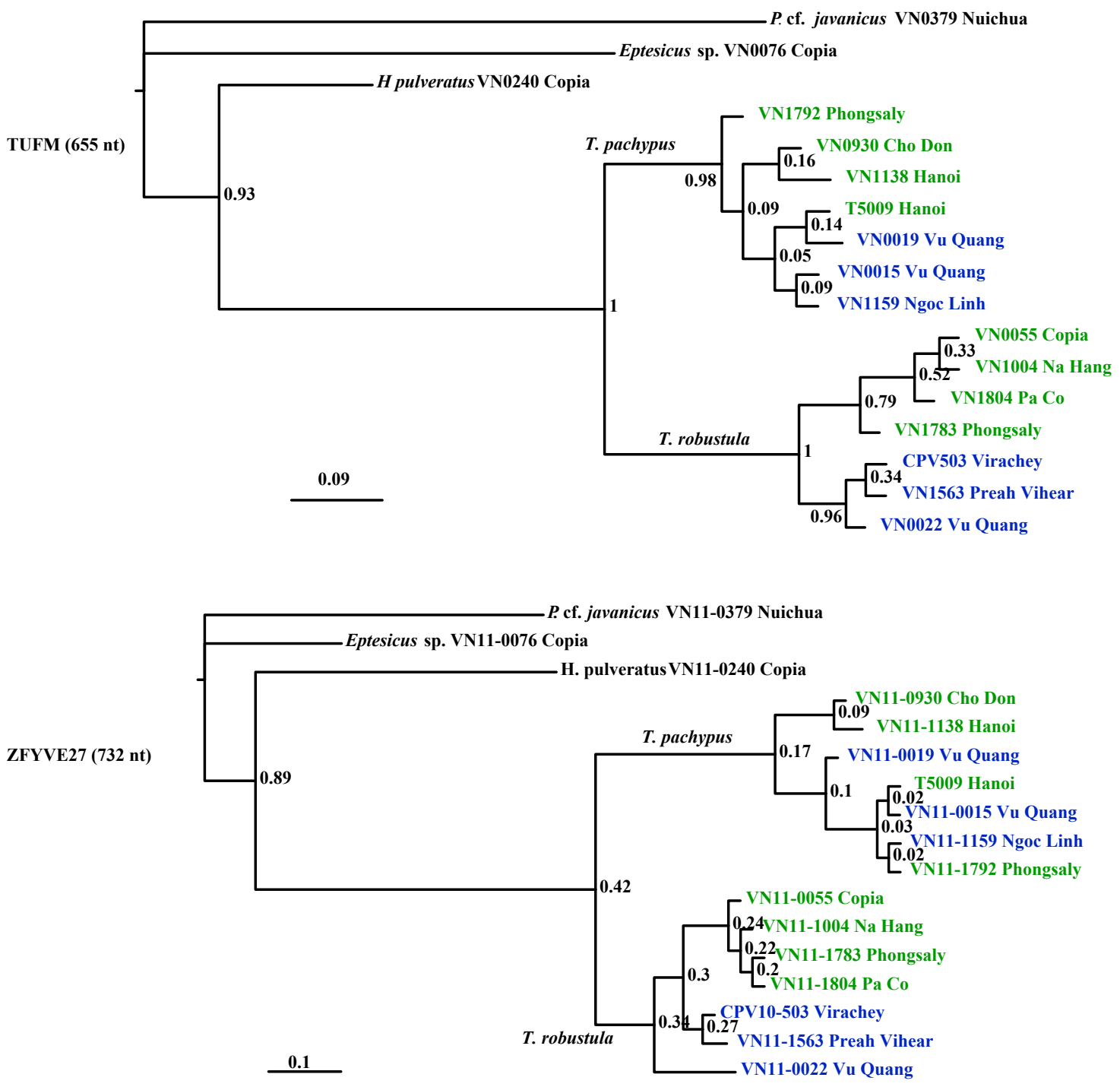